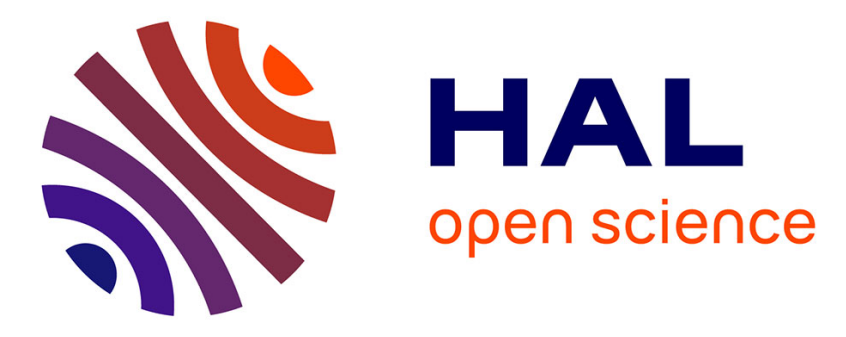

\title{
Hydrogel-Tissue Adhesion Using Blood Coagulation Induced by Silica Nanoparticle Coatings
}

Raphaël Michel, Mailie Roquart, Elodie Llusar, Fabrice Gaslain, Sophie Norvez, Jae Seon Baik, Gi-Ra Yi, Mathieu Manaserro, Laurent Corté

\section{- To cite this version:}

Raphaël Michel, Maïlie Roquart, Elodie Llusar, Fabrice Gaslain, Sophie Norvez, et al.. HydrogelTissue Adhesion Using Blood Coagulation Induced by Silica Nanoparticle Coatings. ACS Applied Bio Materials, 2020, 3 (12), pp.8808-8819. 10.1021/acsabm.0c01158 . hal-03230809

\section{HAL Id: hal-03230809 https://hal.science/hal-03230809}

Submitted on 20 May 2021

HAL is a multi-disciplinary open access archive for the deposit and dissemination of scientific research documents, whether they are published or not. The documents may come from teaching and research institutions in France or abroad, or from public or private research centers.
L'archive ouverte pluridisciplinaire HAL, est destinée au dépôt et à la diffusion de documents scientifiques de niveau recherche, publiés ou non, émanant des établissements d'enseignement et de recherche français ou étrangers, des laboratoires publics ou privés. 


\section{Hydrogel-tissue adhesion using blood coagulation induced by silica nanoparticle coatings}

Raphaël Michel, ${ }^{1+*}$ Maïlie Roquart, ${ }^{1,2}$ Elodie Llusar, ${ }^{1}$ Fabrice Gaslain, ${ }^{2}$ Sophie Norvez, ${ }^{1}$ JaeSeon Baik, ${ }^{3}$ Gi-Ra Yi, ${ }^{3}$ Mathieu Manassero, ${ }^{4,5}$ Laurent Corté ${ }^{1,2 *}$

${ }^{1}$ Molecular, Macromolecular Chemistry, and Materials, ESPCI Paris, CNRS, PSL Research University, 75005 Paris, France

${ }^{2}$ Centre des Matériaux, MINES ParisTech, CNRS, PSL Research University, 91003 Evry, France

${ }^{3}$ School of Chemical Engineering, Sungkyunkwan University, Suwon 16419, Republic of Korea

${ }^{4}$ Service de chirurgie, École Nationale Vétérinaire d'Alfort, 94700 Maisons-Alfort, France.

${ }^{5}$ Laboratoire de Biologie, Bioingénierie et Bioimagerie Ostéo-Articulaire, CNRS UMR 7052, 75010

Paris, France

KEYWORDS: hydrogel, nanoparticle, coating, bioadhesion, hemostasis 


\section{ABSTRACT}

The fixation of hydrogels to biological tissues is a major challenge conditioning the development of implants and surgical techniques. Here, coatings of procoagulant nanoparticles are devised which use the presence of blood to create adhesion between hydrogels and soft internal organs. Those nanostructured coatings are simply adsorbed at the hydrogel surfaces and can rapidly activate the formation of an interfacial blood clot acting as an adhesive joint. This concept is demonstrated on pig liver capsules with model poly(ethylene-glycol) membranes that are intrinsically poorly adhesive. In the absence of blood, ex vivo peeling tests show that coatings with aggregates of bare silica nanoparticles induce a two- to four-fold increase in adhesion energy as compared to the uncoated membrane $\left(3 \pm 2 \mathrm{~J} \cdot \mathrm{m}^{-2}\right)$. This effect is found to scale with the specific surface area of the coating. The highest adhesion energies produced by these nanoparticle-coated membranes $\left(10 \pm 5 \mathrm{~J} . \mathrm{m}^{-2}\right)$ approach the value obtained with cyanoacrylate glue $\left(33 \pm 11 \mathrm{~J} \cdot \mathrm{m}^{-2}\right)$ for which tearing of the tissue is observed. Ex vivo pull-off tests show an adhesion strength of coated membranes around $5 \pm 1 \mathrm{kPa}$, which is significantly reduced when operating in vivo $(1.0 \pm 0.5$ $\mathrm{kPa}$ ). Nevertheless, when blood is introduced at the interface, the in vivo adhesion strength can be improved remarkably with silica coatings, reaching $4 \pm 2 \mathrm{kPa}$ after 40 min contact. In addition, these silica-coated membranes can seal and stop the bleeding produced by liver biopsies very rapidly $(<30 \mathrm{~s})$. Such a combination of coagulation and particle bridging opens promising routes for better biointegrated hydrogel implants and improved surgical adhesives, hemostats and sealants. 


\section{INTRODUCTION}

Fastening hydrogels at the surface of soft internal tissues is of high interest for numbers of surgical procedures including wound healing, ${ }^{1}$ sealing, ${ }^{2}$ stopping bleeding, ${ }^{3}$ delivering drugs or cells, ${ }^{4}$ securing implants. ${ }^{5}$ Existing fixation methods are often poorly satisfactory in that respect: mechanical fasteners like sutures cause damage to both hydrogels and tissues and do not guarantee an intimate contact; polymer glues can be toxic and weakly adhesive in very hydrated situations. ${ }^{6}$ Great progress have been made to design hydrogels that are intrinsically adhesive to biological tissues. $^{7-9}$ The main strategies involve the insertion of moieties in the gel network that can bind covalently $^{9,10}$ or through supramolecular interactions ${ }^{9,11}$ with the structural proteins and polysaccharides of biological tissues. Other, possibly complementary, approaches consist in creating a mechanical anchoring either through the interlocking produced during in situ gelation in the tissue interstices ${ }^{8}$ or through the penetration of preformed surface microtopographies. ${ }^{12,13}$ In addition, the draining of interfacial fluid produced by hydrogel swelling has recently been shown to be a key factor to achieve adhesion onto tissues ${ }^{14}$ and was used to develop superabsorbant double-sided tape with remarkable adhesive performances. ${ }^{15}$ Therefore, there exists a rich variety of intrinsically adhesive hydrogel formulations which can be adjusted to the specific needs of a given tissue and clinical application. An even greater scope of applications might be reached using

tissue-adhesive surface treatments that can be applied to any hydrogel system, independently of its bulk chemical, mechanical and biological properties. In that regard, versatile strategies have recently been proposed either by introducing nanoparticles that adsorb at the hydrogel-tissue interface ${ }^{16}$ or by introducing polymer chains that diffuse and act as molecular stitches. ${ }^{17}$ In all these approaches, the presence of blood wetting the tissue surface is commonly considered as a major complication for the attachment of hydrogels and one must demonstrate that adhesion can be 
achieved even when tissue surfaces have been pre-exposed to blood. ${ }^{10,15}$ Here, we propose on the contrary to exploit the presence of blood as a way to reinforce adhesion between hydrogels and tissues. For that, we devised coatings of procoagulant particles that can be easily deposited onto hydrogel surfaces to (i) provide a large surface for macromolecular adsorption and (ii) induce the rapid formation of a blood clot gluing the coated hydrogel to the underlying tissues.

Our approach uses the principle of particle bridging as first reported by Leibler and coworkers. ${ }^{16,18}$ Placed at the interface between hydrogels and tissues, particles act as connectors due to the adsorption of both hydrogel polymer strands and tissue biomacromolecules onto the surface of the particles. This mechanism of adhesion brings an interesting combination of features for hydrogeltissue fixation, which is difficult to produce with polymer adhesives: it is applicable to a great variety of particles, hydrogels and tissues for which attractive surface interactions promote adsorption; it is rapid and occurs upon simple contact; the interface remains permeable to fluids and bioactive substances; particles can bring other functions to the interface and be used as a platform to make multifunctional adhesives. ${ }^{19,20}$ In vivo experiments on small animal models have shown that particle bridging applies efficiently to biological tissues. ${ }^{18}$ In these seminal studies as well as in works by other groups ${ }^{20-23}$, adhesion to tissues was achieved using different particle types including silica or silica-based particles. Independently, it is worth pointing out that silica particles are also known to strongly accelerate the blood coagulation process. ${ }^{24-26}$ This procoagulant effect is at the basis of hemostatic agents used for emergency care. ${ }^{27,28}$ It is mainly attributed to the electronegativity of silica in physiological conditions leading to the adsorption and conformational change of blood proteins that activate the coagulation cascade leading to the polymerization of a fibrin network. ${ }^{29,30}$ Concurrently, silica nanoparticles were also shown to trigger platelet aggregation due to mechanical mismatch ${ }^{31}$ and activation of platelet surface 
receptors (GIIb/IIIa), ${ }^{32}$ thereby accelerating blood-clot formation. In this work, we combine the mechanism of particle bridging with the procoagulant properties of silica by making adhesive nanostructured coatings composed of aggregates of silica nanoparticles adsorbed at the surface of hydrogel membranes.

Our hypothesis is that the in situ creation of a blood clot at the interface between the coating and the tissue provides additional binding and reinforces the tissue-membrane adhesion. Recent microscopic observations by Shin et al. support this idea and indicate that nanoparticles with a silica shell injected in vivo in liver tissues get preferentially covered by the fibrin fibers forming blood clots. ${ }^{20}$ As a result, one could anticipate that an interfacial blood clot would create adhesion by adsorbing onto the particle coating on one side and by binding covalently to tissue components on the other side. ${ }^{25,26}$ Such a possible contribution of coagulation to adhesion by particle bridging still needs to be measured. We address this question by comparing two situations, as depicted in Figure 1. In situation (a), the coated membrane is placed directly into contact with the serous surface of internal organs: adhesion by particle bridging is expected to occur through the adsorption of polymer chains and tissue macromolecules onto the coating aggregates. In situation (b), blood is introduced at the interface between the coated membrane and the tissue surface. This can be done incidentally as in the case of a bleeding tissue or purposely by wetting the coated membrane with blood prior to deposition. In such a situation, interaction of blood with silica is expected to trigger the formation of a clot, which in turn should act as a biological glue binding strongly to tissues through the covalent cross-linking of fibrin and structural macromolecules of the tissues such as collagen and fibronectin. ${ }^{33,34}$ 

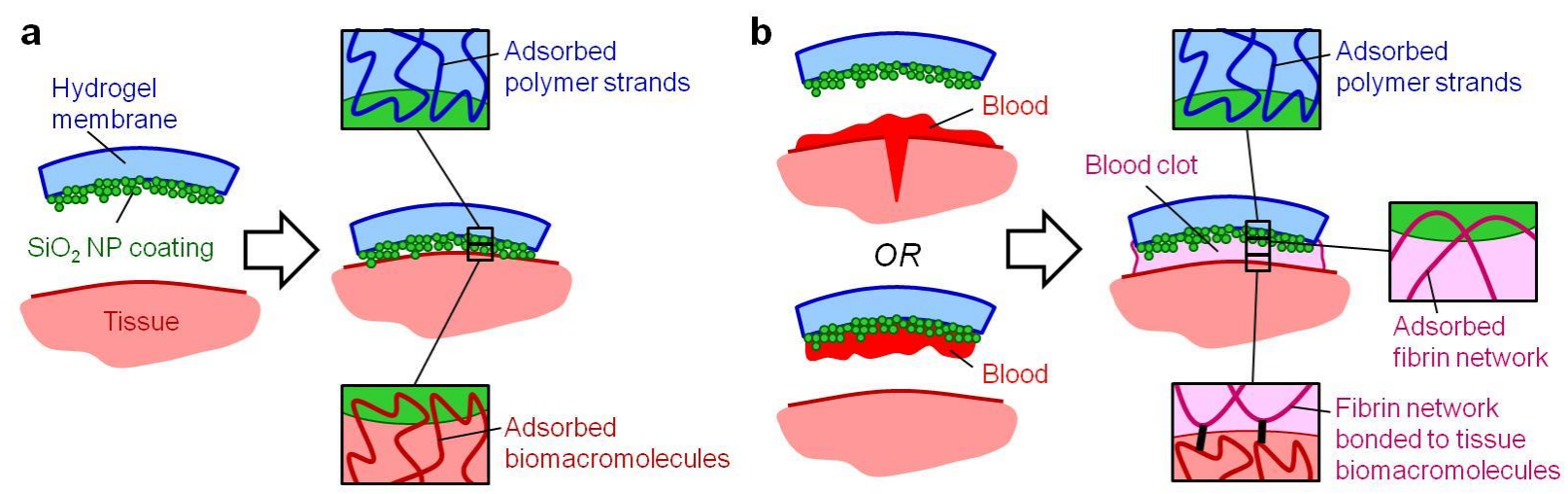

Figure 1: Principle of bioadhesive particle coatings (a) without and (b) with interfacial blood.

This model study concentrates on the adhesion produced on the capsule of porcine liver, which is a commonly used model to assess the performance of surgical adhesives. ${ }^{10,35,36}$ In order to quantify specifically the interfacial phenomena governing membrane-tissue adhesion, it is important to distinguish them from other dissipative processes that may occur in the bulk of polymer adhesives. For that, we used model polyethylene glycol (PEG) films to be coated with silica nanoparticle aggregates. These elastic films exhibit an almost purely elastic behavior so that the contribution of bulk dissipation in the debonding process is negligible and the measured work of adhesion essentially corresponds to the mechanisms occurring near the interface. As a consequence, these hydrogels are intrinsically poor tissue adhesives. In particular, the typical adhesion energies achievable with these model membranes ought to be significantly smaller (1-10 J.m $\left.{ }^{-2}\right)$ than those obtained with optimized adhesives $\left(>100 \mathrm{~J} . \mathrm{m}^{-2}\right)$, for which most of the adhesion energy is associated to dissipative mechanisms in the bulk. ${ }^{37}$

In the following, we compare coatings produced with a simple brush-spreading process using different silica nanoparticles. Ex vivo peeling experiments show that the adhesion energy produced 
on the liver capsule can be adjusted by controlling the specific surface area of the coatings. The two coatings yielding the highest ex vivo adhesion were used for in vivo experiments which are more indicative of the hydrated state of biological tissues and reproduce the coagulation process encountered in surgical conditions. For the first time, adhesion by particle bridging is quantified in vivo. A strong decrease in adhesion strength is observed as compared to the one recorded ex vivo. Nevertheless, we show that adhesion is very significantly enhanced if blood is present at the interface between silica-coated hydrogels and the serous surface of the liver capsule. We investigate the potential of this approach for hemostatic applications and show that silica-coated membranes rapidly stop the abundant bleeding created in a porcine hemorrhage model. Based on these data, we discuss the relevance of such particle coatings for the design of adhesive hydrogeltissue interfaces in the perspective of internal surgical use. 


\section{EXPERIMENTAL SECTION}

\subsection{Materials}

The chemicals used in this work were used as purchased without further purification. Ethanol $(\geq$ 99.8\%), pentaerythritol tetrakis (3-mercaptopropionate) (QT, $\geq 95 \%$ ), poly(ethylene glycol) diacrylate (PEGDA, $\mathrm{M}_{\mathrm{n}}=700 \mathrm{~kg} \cdot \mathrm{mol}^{-1}$ ) were purchased from Sigma-Aldrich. (3-Aminopropyl) trimethoxysilane (APTMS, 97\%), triethylamine (TEA, $\geq$ 99\%), 1,6-hexanedithiol (HT, 97\%), $\mathrm{NH}_{3} . \mathrm{H}_{2} \mathrm{O}(28 \%$ ), and tetraethyl orthosilicate (TEOS) were purchased from Alfa Aesar. (N(trimethoxysilylpropyl) ethylenediamine-triacetic acid-trisodium salt (35\% in water) was purchased from Gelest. Oxidized regenerated cellulose mesh (Surgicel ${ }^{\circledR}$ ) was purchased from Ethicon. Sterile gauze pads (Medicomp ${ }^{\circledR} 10 \times 10 \mathrm{~cm}$ ) were purchased from Hartmann. The surgical cyanoacrylate glue GLUture $^{\circledR}$, containing $60 \%$ 2-octyl cyanoacrylate and $40 \%$ N-butyl cyanoacrylate, was purchased from Zoetis.

\subsection{Ex vivo liver tissues}

Porcine livers for ex vivo adhesion experiments were harvested from freshly killed 3-month old pigs (Sus scrofa domesticus, approx. $25 \mathrm{~kg}$ ) at the École de Chirurgie du Fer-à-Moulin (AP-HP) in accordance with the principles of animal care. Whole livers were transported in a cooler and were stored at $4^{\circ} \mathrm{C}$ in physiological serum. They were used between 2 and 30 hours following their harvesting. Tissues were not stored in the freezer at any time as this is known to alter their

integrity. ${ }^{38}$ During those storage times, no significant evolution of the adhesive properties was observed.

\subsection{PEG hydrogel fabrication and characterization}

PEG membrane fabrication for peeling experiments. The PEG hydrogel films were prepared and characterized using a previously used protocol. ${ }^{14}$ Poly(ethylene glycol)diacrylate (PEGDA) was 
cross-linked with a mixture of hexanedithiol (HT) and pentaerythritol tetrakis(3mercaptopropionate) (QT) in 15 wt.\% ethanol and using triethylamine (TEA) as catalyst. The monomers were combined in a ratio (PEGDA/HT/QT: 24/22/1) so that acrylate groups and thiol groups were present in equal quantities. The concentration of TEA was adjusted as to account for $1 \mathrm{~mol} \%$ of all thiol groups.

PEGDA, HT and the corresponding fraction of TEA were first mixed at $21^{\circ} \mathrm{C}$ and left to react under stirring (150 rpm) until conversion of $90 \%$ of acrylate groups is achieved (as confirmed by infrared spectroscopy). QT, ethanol, and the remaining TEA were then added to the mixture and further stirred at the same temperature for 10 minutes. The mixture was injected in rectangular glass molds of $100 \mathrm{~mm} \times 80 \mathrm{~mm} \times 1.1 \mathrm{~mm}$. The molds were sealed with silicone and stored for 5 days at room temperature $\left(20 \pm 2^{\circ} \mathrm{C}\right)$. After removal from the molds, the hydrogel films were vacuum-dried until complete evaporation of the ethanol and triethylamine. They were then thoroughly washed by immersion $(>3 \mathrm{~h}$ ) in ultrapure water to eliminate the extractible soluble fraction $(<0.1$ wt.\%). The washed hydrogel membranes were subsequently dried in an oven at $60^{\circ} \mathrm{C}$ until complete water evaporation. The resulting dry PEG films had a thickness of $1 \pm 0.03$ $\mathrm{mm}$. Samples for ex vivo peeling tests were obtained by cutting rectangular ribbons having a 10cm length and 1-cm width.

PEG membrane fabrication for in vivo experiments. For in vivo experiments, thinner PEG films (0.5-mm thickness) were molded following the same protocol as described above. In this case, the PEG films were reinforced with a sterile gauze pad inserted in the mold. For pull-off experiments, samples were obtained by cutting 16-mm diameter discs. A 5-mm diameter disc of transparency film was glued with cyanoacrylate glue on one side in the center of the PEG disc to ensure a reproducible attachment area. A small metal nut attached to a thin nylon thread loop was then 
glued on top of this disc using cyanoacrylate glue one day before the experiments. For hemostasis experiments, 24-mm diameter discs were used.

\subsection{Nanoparticle synthesis}

SiO-10 and SiO-30 (Ludox nanoparticles). Ludox ${ }^{\circledR}$ TM-50 and SM-30 (colloidal silica suspension with particle diameters of $30 \mathrm{~nm}$ and $10 \mathrm{~nm}$ respectively) were purchased from Sigma Aldrich. Before use, the nanoparticle solutions were dialyzed for two days in $1 \mathrm{~L}$ of ultrapure water using VISKING ${ }^{\circledR}$ dialysis tubes (obtained from Carl Roth with a molecular weight cut-off of 12-14 $\mathrm{kDa}$ ), renewing the water at least five times during this period.

SiO-100 and SiO-300 (Stöber method). Silica particles of $100 \mathrm{~nm}$ and $300 \mathrm{~nm}$ were synthetized by the Stöber method. ${ }^{39}$ Ammonium hydroxide (28 wt\%) and ultrapure water were diluted in $800 \mathrm{~mL}$ of ethanol in a round-bottom flask and homogenized for $15 \mathrm{~min}$. The diameter of the particles was adjusted depending on the amount of ammonium hydroxide (100 nm: $48 \mathrm{~mL}, 300 \mathrm{~nm}: 72 \mathrm{~mL})$ and water (100 nm: $21 \mathrm{~mL}, 300 \mathrm{~nm}: 0 \mathrm{~mL})$ in the reactor. Then, $24 \mathrm{~mL}$ of TEOS was added to the mixture which was stirred for $24 \mathrm{~h}$ at $25^{\circ} \mathrm{C}$. The so-obtained colloidal solutions were then dialyzed using the same procedure as for $\mathrm{SiO}-10$ and $\mathrm{SiO}-30$ nanoparticles.

SiO-MP-50 and SiO-MP-75 (Mesoporous silica nanoparticles). Mesoporous silica nanoparticles with 50 - and 75-nm diameter and 6-nm pores were synthesized using polymer and silane inside miniemulsion as previously reported by Nandiyanto et al. ${ }^{40}$ with some modifications. At first, $1 \mathrm{~g}$ of CTAB (cetyltrimethylammonium bromide) was dissolved in $300 \mathrm{~mL}$ of deionized water while maintaining the temperature at $65^{\circ} \mathrm{C}$. After the surfactant was dissolved, $144 \mathrm{~mL}$ of octane was added into the solution under nitrogen atmosphere for $30 \mathrm{~min}$. Then, $0.5 \mathrm{~g}$ of styrene, $0.22 \mathrm{~g}$ of Llysine, $10 \mathrm{~g}$ of TEOS (tetraethyl orthosilicate), and $0.372 \mathrm{~g}$ of AIBA (2,2'-azobis (2methylpropionamidine) dihydrochloride) were added into the reactor and stirred for $3 \mathrm{~h}$. The 
diameter of the nanoparticles was adjusted to 50 and $75 \mathrm{~nm}$ depending on the amount of silane in the reactor. The so-synthesized nanoparticles were collected by centrifugation at 12,000 rpm for 20 min and washed three times in ethanol. The polymer templates became mesopores by a heat treatment at $500^{\circ} \mathrm{C}$ for $5 \mathrm{~h}$. The mesoporous silica nanoparticles were re-dispersed in water to produce $\mathrm{SiO}-\mathrm{MP}-50$ and $\mathrm{SiO}-\mathrm{MP}-75$ solutions.

\subsection{Nanoparticle characterization}

Dynamic Light Scattering (DLS). Nanoparticle size was measured by Dynamic Light Scattering using an ALV/CGS-3 Compact Goniometer system with an ALV/LSE-5004 multiple tau digital correlator (ALV, Langen, Germany), using a $90^{\circ}$ scattering geometry and a $632 \mathrm{~nm}$ laser diode. All experiments were done in a thermostatic bath at $25 \pm 0.1^{\circ} \mathrm{C}$. Nanoparticle solutions were diluted down to $0.01 \mathrm{wt} \%$ before the measurement to avoid multiple scattering. The mean hydrodynamic radius of the particles was calculated using the cumulant method.

Specific Surface Area (SSA). For the plain nanoparticles (SiO-10, SiO-30, SiO-100, SiO-300), the specific surface area was calculated by $S S A=6 / \rho . d$ where $\rho$ is the density of amorphous silica $(2.2$ g.cm ${ }^{-3}$ ) and $d$ is the mean diameter of the particles. For the mesoporous nanoparticles (SiO-MP50, SiO-MP-75), the size and mesoporous structures were characterized by scanning and transmission electron microscopy, and the specific surface area and pore volume were measured by the Brunauer-Emmett-Teller method. ${ }^{21}$

\subsection{Coating preparation and characterization}

Nanoparticle aggregation. Powders of microscopic nanoparticle aggregates were obtained from the dialyzed particle suspensions as follows. First, small volumes of the particle solutions (10 to $20 \mathrm{~mL}$ ) were left to dry in an oven at $80^{\circ} \mathrm{C}$ until complete solvent evaporation (less than $1 \mathrm{mg}$ variation in dry extract mass between two consecutive $4 \mathrm{~h}$ drying steps). The solid aggregates were 
then ground in an agate mortar and the powder was sieved through a $63-\mu \mathrm{m}$ mesh size aluminum sieve.

Coating deposition. Coatings were produced by depositing an excess of nanoparticle powder at the surface of the dry PEG membranes $\left(4 \mathrm{mg} \cdot \mathrm{cm}^{-2}\right)$. The powder was subsequently spread on the whole membrane surface with a brush and the excess powder which did not adhere to the PEG was removed. Aggregates were left to adsorb on the hydrogel membrane for $5 \mathrm{~min}$ before contact with the liver capsule. In the case of the surgical cyanoacrylate glue GLUture ${ }^{\circledR}$, a few drops of glue on the PEG were spread on the membrane surface with a needle $\left(4.7 \pm 0.5 \mathrm{mg} . \mathrm{cm}^{-2}\right)$. This deposition step was performed in less than 20 seconds to limit the polymerization of the glue prior to its contact with tissues.

Area density of deposited coating. The quantity of deposited coating $m_{c}$ was expressed as a mass of coating per unit area of PEG membrane $\left(\mathrm{mg} \cdot \mathrm{cm}^{-2}\right)$ and was given by $m_{c}=\left(M_{a c}-M_{b}\right) / S_{c}$, where $M_{a c}$ is the mass of the membrane after coating deposition, $M_{b}$ is the mass of the bare membrane, and $S_{c}$ is the area of the coated film surface.

Scanning electron microscopy (SEM). The surface of the coated membranes was characterized by scanning electron microscopy (SEM) on a FEI Nova NanoSEM 450 apparatus operating at an accelerating voltage of $2 \mathrm{kV}$. Observations were performed with a secondary electron TLD detector on dry PEG membranes. Before SEM imaging, specimens were sputter coated with a 2 nm layer of gold/palladium to make the coated membranes conductive.

Coating stability in liquid. Dry PEG membranes coated with SiO-10 or SiO30 silica nanoparticles were immersed in a large volume of ultrapure water $\left(20 \mathrm{~mL} \cdot \mathrm{cm}^{-2}\right)$ under agitation $(200 \mathrm{rpm})$ at room temperature for 5, 30 and $60 \mathrm{~min}$. Membranes were then dried in a vacuum oven at $40^{\circ} \mathrm{C}$ 
until complete water evaporation indicated by mass stabilization. The remaining coating mass per unit area of PEG membrane $\left(m_{c}\right)$ was evaluated by weighting the membranes after the drying step.

\subsection{Ex vivo adhesion measurement}

Protocols are the same as those described previously. ${ }^{14}$

Preparation of liver substrate and deposition of peeling ribbons. Ex vivo adhesion measurements were performed on the liver capsule. For that, rectangular liver samples were cut from liver lobes with typical dimensions $100 \mathrm{~mm} \times 30 \mathrm{~mm} \times 10 \mathrm{~mm}$ using a sharp knife. For each measurement, the whole protocol was timed from liver sample cutting to peeling in order to avoid variations due to tissue drying. Each liver sample was first immersed twice for $30 \mathrm{~s}$ in physiological serum. This gentle washing removed traces of coagulated blood that may influence adhesive properties and ensured a reproducible wetting of the tissue surface. Then, one minute after the second tissue immersion in physiological serum, the bottom face of the liver sample was glued onto a flat holder using cyanoacrylate glue with the capsule surface exposed to air on the top face. Uncoated or coated dry PEG ribbons were deposited at the surface of liver samples 3 min after the end of the second tissue immersion in physiological serum. A pressure was applied repeatedly with one finger during the first minute of contact over the whole contact area while measuring the force with a weighing scale. A maximum force of $6 \mathrm{~N}$ was applied at each finger pressure, which corresponds approximately to a $80 \pm 50 \mathrm{kPa}$ pressure when approximating the finger contact area to a disc having a $6 \pm 2 \mathrm{~mm}$ radius. The ribbons were left in contact with the liver capsule for exactly $5 \mathrm{~min}$ prior to peeling.

Peeling experiment. Peeling experiments were performed on tensile test apparatus (All Around, Zwick) equipped with a $90^{\circ}$ peeling device and a $10 \mathrm{~N}$ load cell. All peeling experiments were performed at $1 \mathrm{~mm} / \mathrm{s}$. The system was synchronized with video cameras to record side and front 
views of the peeling zone. For each type of silica coating, experiments were repeated 3-6 times on several different livers $(\mathrm{N}=3-6)$.

Correction and normalization of peeling force. The peeling force was systematically corrected by subtracting the weight of the lifted ribbon. The corrected force was given by $F=F^{*}-\rho d$ where $F^{*}$ is the raw peeling force as measured by the cell force, $d$ the displacement and $\rho$ the linear mass of the ribbon. In all the work, the normalized corrected peeling force, $F / w$, is used, where $w$ is the width of the peeled ribbon.

Calculation of adhesion energy. Adhesion energy, $G$, was obtained from peeling measurements considering elastic peeling of a thin film ${ }^{41}$ For that, we verified that the bending contributions are negligible. ${ }^{42}$ In each experiment, a steady state was reached with a constant peeling profile and a peeling angle equal to $90^{\circ}$ after the first 10 to $20 \mathrm{~mm}$ of displacement. An average peeling force was measured by averaging the value of the corrected force during this steady state regime. For $90^{\circ}$ peeling angle, the adhesion energy of one peeling experiment is then given by $G=<F>/ w$ where $\langle F>$ is the average corrected force during steady state peeling.

\subsection{In vivo evaluation of adhesion and hemostasis}

Animals. A total of 5 healthy, one-year-old, Pré-Alpes pig (Sus scrofa domesticus) weighing 60$70 \mathrm{~kg}$ were obtained from a licensed vendor (Lebeau Christian, Neuves-Maisons, France). The pig model was selected as the experimental species because of its similarity to humans when monitoring and measuring physiological responses during the procedure. These pigs were cared for in accordance with the guidelines published by the European Committee for "Care and Use of Laboratory Animals" (Directive 2010/63/EU and the European Convention ETS 123). All procedures were performed in compliance with legislation concerning animal experimentation and 
approved by the Ethics Committee on Animal Research of ANSES/ENVA/UPEC (C2EA-16, referral number 18-029, 2018030517071534 (\# 13915)).

Surgical protocol. Food was withheld throughout the day and overnight prior to surgery. General anesthesia was induced with intramuscular injection of xylazine $(1.5 \mathrm{mg} / \mathrm{kg})$, ketamine $(15 \mathrm{mg} / \mathrm{kg})$ followed by intravenous injection of propofol $(4 \mathrm{mg} / \mathrm{kg}$ titrated to effect). After orotracheal intubation, anesthesia was maintained using isoflurane in $\mathrm{O}_{2}$. Analgesia was performed by intravenous injection of morphine chlorhydrate $(0.3 \mathrm{mg} / \mathrm{kg}$, redosing to effect).

Animals were ventilated and vital signs (temperature, heart rate, respiration rate, peripheral capillary oxygen saturation, capnography, indirect blood pressure) were monitored and Lactated Ringer's solution was administered intravenously throughout the procedure.

Each pig underwent a ventral midline laparotomy using standard surgical techniques. Briefly, the midline laparotomy was performed from the xiphoid process to the umbilicus. Self-retaining retractors and wetted laparotomy sponges were placed on the abdominal muscular edges. The liver was exposed and left medial, right medial, and left lateral lobes were isolated and wrapped with moist laparotomy sponges.

After completion of surgical procedures and while under anesthesia, animals were euthanized by intravenous injection of a sodium pentobarbital-based solution, consistent with the recommendations of the American Veterinary Medical Association (AVMA) Panel on Euthanasia. ${ }^{43}$

Pull-off adhesion measurements. The uncoated or coated discs were applied on the liver capsule to the designated liver lobe and held by gentle digital pressure for 30 seconds with the same pressure level as the one applied for ex vivo experiments $(80 \pm 50 \mathrm{kPa})$. Attachment sites were chosen 1-2 cm apart, to prevent cross-contamination. After a given time of contact (10 or $40 \mathrm{~min}$ ), 
the discs were detached by pulling on the nylon thread loop using a portable dynamometer (FK10 dynamometer from Sauter with a $5 \mathrm{mN}$ resolution). Pulling was applied manually by the same operator in a direction perpendicular to the tissue surface at an approximate speed of $100 \mathrm{~mm} \cdot \mathrm{s}^{-1}$. The dynamometer allowed to record the maximum force $\left(F_{\max }\right)$ reached during this detachment process.

Ex vivo pull-off experiments were performed for comparison using a tensile test apparatus (All Around, Zwick) equipped with a $10 \mathrm{~N}$ load cell. Measurements were performed at a pulling speed of $1 \mathrm{~mm} \cdot \mathrm{s}^{-1}$. Force-displacement curves during pulling-off were recorded and allowed for the determination of the maximum force reached during this detachment process. Control experiments using manual dynamometer on ex vivo livers gave similar results.

Adhesion with interfacial blood layer. In vivo adhesion measurements were also performed after wetting the surface of the membranes with fresh blood. For that, a small bleeding incision (about $2 \mathrm{~cm}$ long and $5 \mathrm{~mm}$ depth) was performed with a $\mathrm{N}^{\circ} 11$ blade on the spleen through the capsule and the parenchyma. The free surface of the discs (the one without the attached metal nut) was subsequently rubbed on the bleeding incision so as to cover it with a layer of fresh liquid blood. The membrane was deposited immediately after on the liver capsule and maintained on the tissues under gentle manual pressure for $30 \mathrm{~s}$. The adhesion strength was measured after a given contact time (10 or $40 \mathrm{~min})$.

Evaluation of hemostatic performance. Biopsies were performed on the liver capsule in vivo with a biopsy punch creating wounds of $6 \mathrm{~mm}$ diameter and $5 \mathrm{~mm}$ depth. Experiments were performed on three pigs. First, the bleeding rate of each biopsy was measured by weighing gauze pads having collected the blood streaming out of the wound for 1-2 min. Immediately after removing the last gauze pad, a patch made of coated or uncoated PEG disc (diameter: $24 \mathrm{~mm}$ ) or an ORC mesh 
(square of $20 \times 30 \mathrm{~mm}$ composed of two layers of Surgicel ${ }^{\circledR}$ hemostatic gauze) was applied on top of the bleeding wound by the surgeon and firmly maintained on the tissues under manual pressure for $30 \mathrm{~s}$. The sealing performance was assessed during the first 3 min of contact by collecting with gauze pads the blood leaking below the applied patches and weighing them. After $10 \mathrm{~min}$ of contact the coated or uncoated PEG discs and the ORC mesh were removed by a slow manual peeling. The resumption of the bleeding after removal was documented by taking photographs of the wound.

\subsection{Blood clotting kinetics.}

The procoagulant effect of silica nanoparticles was assessed during in vivo operations on two pigs. Blood was harvested in a sterile syringe by venous catheterization from the anesthetized pigs. Blood was poured in 3 testing tubes $(3 \mathrm{~mL})$ within a minute after sampling: one empty tube, one tube with $1 \mathrm{wt} \% \mathrm{SiO}-30$ powder, one tube with $1 \mathrm{wt} \% \mathrm{SiO}-\mathrm{MP}-75$ powder. Mixing was performed by flipping each tube upside down 5 times. Tubes were then placed in a thermostatic bath at $37^{\circ} \mathrm{C}$. Tubes were then extracted from the bath and tilted horizontally every $30 \mathrm{~s}$ approximately. A picture was taken to record the appearance of a blood clot. Clotting time corresponds to the duration after which the blood is no longer flowing upon tilting.

\subsection{Statistical Analysis}

Statistical analysis was carried out on ex vivo and in vivo adhesion measurements. A Shapiro Wilk test was performed to determine if both populations follow a normal distribution. When normality was verified, raw data were analyzed using an unpaired t-test. Statistical significance was accepted at the level of $\mathrm{p}<0.05$. 


\section{RESULTS AND DISCUSSION}

\subsection{Design of nanoparticle-coated hydrogel membranes}

Model membranes were obtained by coating polyethylene glycol (PEG) films with a layer of nanoparticle aggregates. In contact with aqueous media, these cross-linked PEG films swell and form hydrogel films with a swelling ratio $Q_{e q}=2.00 \pm 0.05$ at equilibrium in water. They exhibit an elastic behavior with a Young's modulus ranging from $E=1 \mathrm{MPa}$ in the dry state to $0.5 \mathrm{MPa}$ at equilibrium swelling (Figure S1). Such hydrogel films differ from intrinsically adhesive hydrogels which are more dissipative and softer $(E<100 \mathrm{kPa})$. Therefore, they are not expected to be strongly adherent to biological tissues, and the adhesion measured when coated may be attributed selectively to the contribution of the particle coating to the debonding processes. Several types of silica nanoparticles were compared to select the most adhesive coatings. Their main features are summarized in Table 1. Nonporous "plain" silica nanoparticles having diameters of $10,30,100$ and $300 \mathrm{~nm}$ are referred to as $\mathrm{SiO}-10, \mathrm{SiO}-30, \mathrm{SiO}-100$ and $\mathrm{SiO}-300$, respectively. Mesoporous silica nanoparticles having a pore size of $6 \pm 3 \mathrm{~nm}$ and diameters of 50 and $75 \mathrm{~nm}$ are referred to as SiO-MP-50 and SiO-MP-75, respectively. As compared to plain particles having about the same size, these porous particles exhibit a much larger specific surface area ( $S S A)$ of the order of $500-700 \mathrm{~m}^{2} \cdot \mathrm{g}^{-1} \cdot{ }^{21}$ For each particle type, powders of microaggregates having a characteristic size smaller than $100 \mu \mathrm{m}$ were prepared from aqueous suspensions through a series of steps comprising dialysis, drying, grinding, and sieving. As expected for silica particles, ${ }^{24-32}$ both plain and mesoporous particle powders exhibit a strong procoagulant effect. This is shown in Figure 2a comparing the coagulation times of whole blood with that of blood mixed with $1 \mathrm{wt} \%$ powders of SiO-30 or SiO-MP-75 (see Figure S2 and Video S1). 


\begin{tabular}{|l|l|c|c|}
\hline Reference & Bulk state & $\mathbf{d}(\mathbf{n m})$ & SSA $\left(\mathbf{m}^{2} \cdot \mathbf{g}^{-1}\right)$ \\
\hline SiO-300 & Plain & 300 & $10 \pm 5$ \\
SiO-100 & Plain & 100 & $30 \pm 10$ \\
SiO-30 & Plain & 30 & $90 \pm 30$ \\
SiO-10 & Plain & 10 & $260 \pm 80$ \\
SiO-75-MP & Mesoporous & 75 & $510 \pm 100$ \\
SiO-50-MP & Mesoporous & 50 & $670 \pm 100$ \\
\hline
\end{tabular}

Table 1: Characteristics of studied silica nanoparticles. d: particle diameter, SSA: specific surface area.
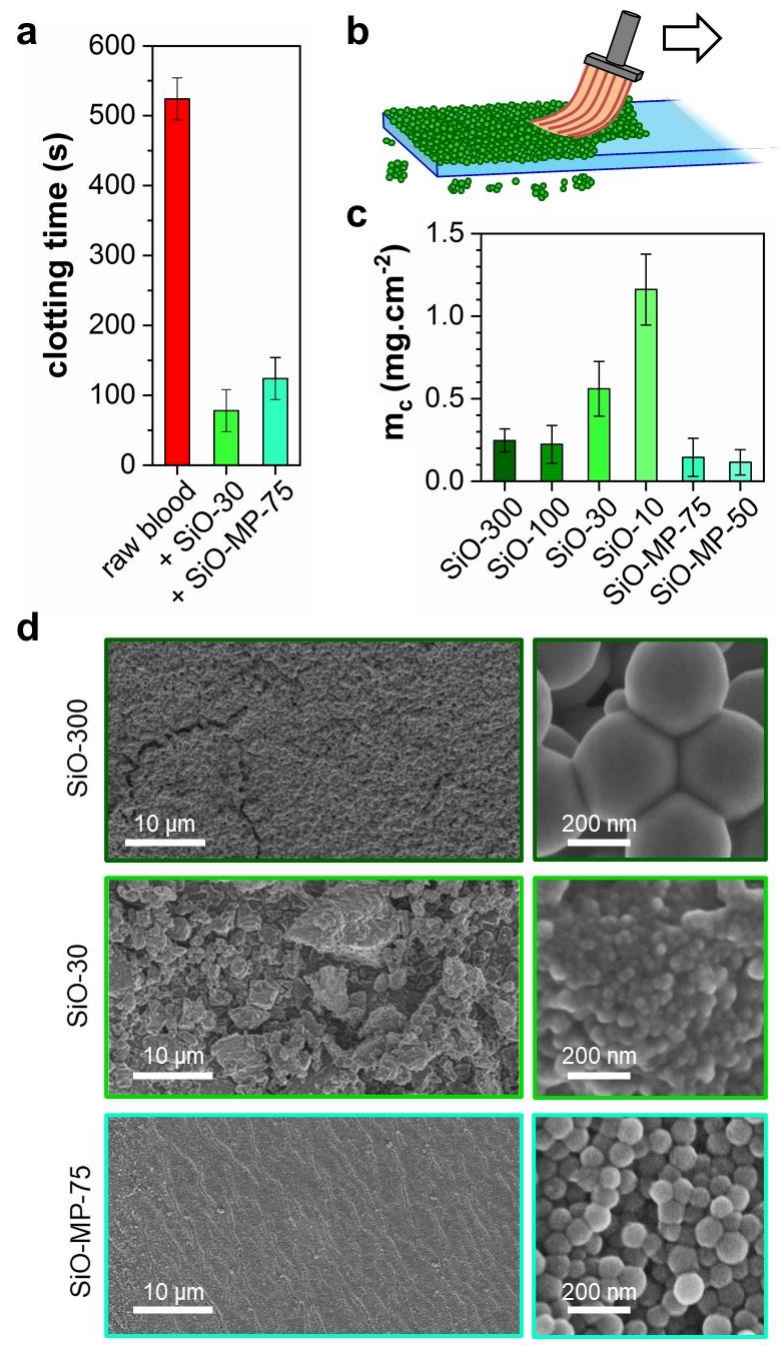

Figure 2: Coating characteristics. (a) Clotting time of raw pig blood and after mixing with $1 \mathrm{wt} \% \mathrm{SiO}-30$ and SiO-MP-75 powders; (b) Schematic representation of the brush-coating process; (c) Area density of coating, $m_{c}$, for the studied nanoparticles; (d) SEM observations of the coated surface of membranes with SiO-300, SiO-30 and SiO-MP-75 nanoparticle aggregates. (left: low magnification showing aggregates, right: high magnification showing nanoparticles). 
Coatings were performed by spreading an excess of nanoparticle powder on the PEG film surface and removing weakly adsorbed aggregates with a brush, as illustrated in Figure 2b. With this simple protocol, the coverage of the film surface reaches saturation. Nevertheless, the mass of coating deposited per unit area $m_{c}$ varies significantly from one nanoparticle type to another as shown in Figure 2c. These variations can be related to differences in the aggregability of the nanoparticles, as indicated by SEM observations in Figure 2d and Figure S3. For the largest particles (SiO-100, SiO-300, SiO-MP-50 and SiO-MP-75), brush spreading produces smooth and thin $\left(m_{c} \sim 0.1-0.2 \mathrm{mg} . \mathrm{cm}^{-2}\right)$ coatings. On the contrary for the smallest particles (SiO-10, SiO-30), aggregates are more cohesive as already observed for spray drying of silica ${ }^{44}$ and explained by their relative higher surface potential. ${ }^{45}$ In this case, the coatings consist in rough and thick $\left(m_{c}>\right.$ $0.3 \mathrm{mg} . \mathrm{cm}^{-2}$ ) stacks of microscopic aggregates.

The strength of nanoparticle adsorption on hydrogel surfaces depends on the nature of the polymer and particle surface chemistries. ${ }^{16}$ In the present PEG-silica systems, a strong affinity is known to exist due to hydrogen bonding interactions between the PEG oxygen atoms and the silica surface hydroxyls ${ }^{46}$ In concentrated aqueous solutions of PEG and silica, PEG chains were shown to be strongly adsorbed onto silica nanoparticles despite the presence of water ${ }^{47}$ Here, we characterize the stability of the adsorbed coatings by immersing SiO-10 and SiO-30 coated PEG films in an excess of water under vigorous steering. Figure 3a shows the evolution of $m_{c}$ as a function of immersion time. After a short immersion time $(<5 \mathrm{~min})$, about $20 \%$ of the silica coating is detached, which we attribute to poorly anchored aggregates that were not brushed away during the deposition process. Once this fraction of particles is detached, the mass of deposited coating remains stable. Therefore, the silica aggregates physically adsorbed on PEG films are not easily 
washed away during rehydration of the hydrogel substrate, as shown previously for silica nanoparticles adsorbed on poly(dimethylacrylamide) gels. ${ }^{16}$ This stability is further confirmed by SEM observations revealing that the surface of the coated films is fully covered by silica aggregates even after 30 min immersion in water, as shown in Figure $\mathbf{3 b}$.
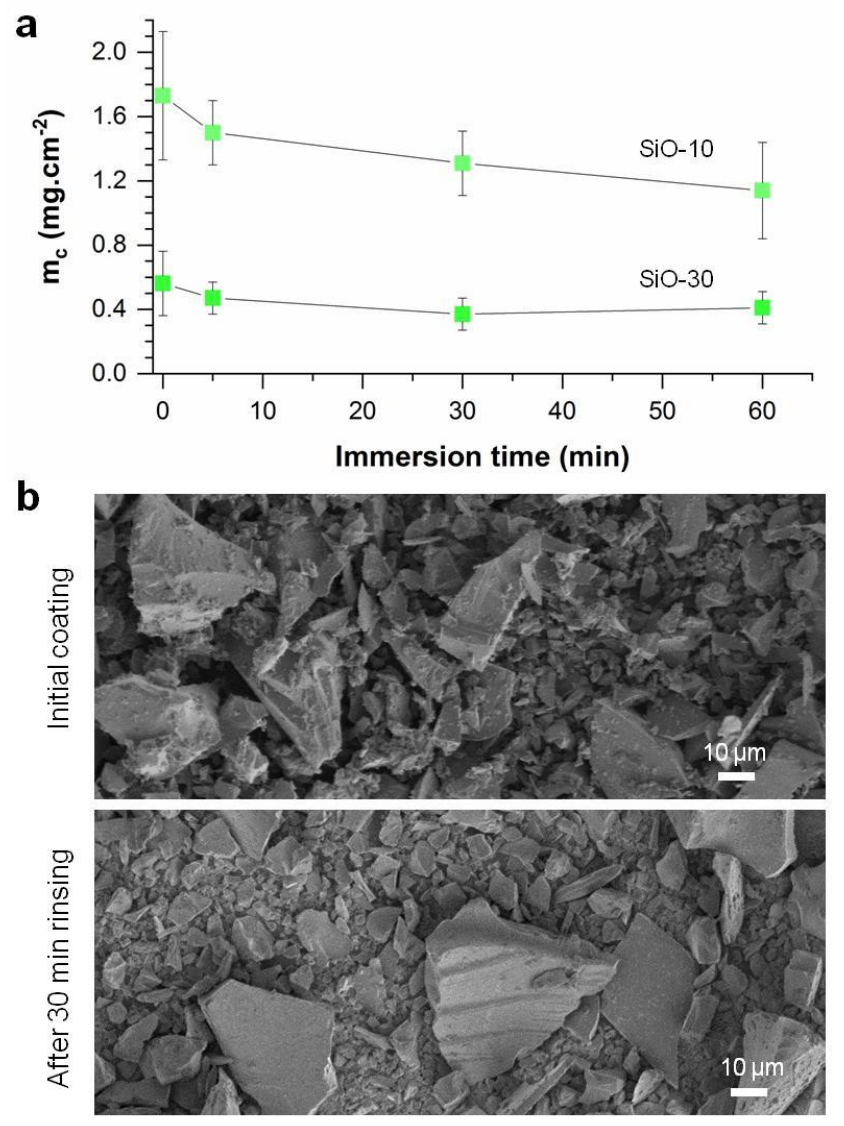

Figure 3: Coating stability in excess water. (a) Evolution of coating mass as a function of immersion time in water for SiO-10 and SiO-30 particles; (b) SEM observations of SiO-10 coatings before and after 30 min immersion in water.

\subsection{Coating selection by ex vivo adhesion}

The bioadhesive performances of the different coatings were first compared ex vivo by $90^{\circ}$ angle peeling experiments on freshly explanted pig livers, as depicted in the inset of Figure 4a. For each measurement, the wetting state of the liver capsule was controlled by immersing the liver samples 
for $1 \mathrm{~min}$ in physiological serum, 3 min prior to deposition of the PEG films. Figure 4a shows typical peeling forces after a 5 min contact on the liver capsule for some silica coated and uncoated PEG films as well as for PEG films glued with surgical cyanoacrylate glue (see Figure S4 for full data). For the uncoated PEG films, a normalized peeling force of about $3 \mathrm{~N} \cdot \mathrm{m}^{-1}$ is obtained and peeling is accompanied by a small deformation of the liver tissue, as shown in Figure $\mathbf{4 b}$ (top) and Video S2. For the silica coated films, the peeling force can be 4 to 5 times higher with a larger deformation of the liver tissue, as shown in Figure $\mathbf{4 b}$ (middle) and Video $\mathbf{S 3}$ in the case of the SiO-30 coating. For the cyanoacrylate glue, the peeling force is substantially higher with large fluctuations ranging from 10 to $40 \mathrm{~N} \cdot \mathrm{m}^{-1}$. In this latter case, detachment is accompanied by tearing of the liver tissue, as shown in Figure $\mathbf{4 b}$ (bottom) and Video S4.

The corresponding values of adhesion energy $G$ are displayed in Figure 4c. For all the coatings except for the smallest nanoparticles ( $\mathrm{SiO}-10)$, adhesion is noticeably enhanced as compared to the uncoated hydrogel $\left(3 \pm 2 \mathrm{~J}_{\mathrm{m}} \mathrm{m}^{-2}\right)$. This effect ranges from a 2-fold increase for the weakest coatings (SiO-300) to a nearly 4-fold increase for the strongest ones (SiO-30, SiO-MP-75, SiOMP-50) with values of the order of $10 \pm 5 \mathrm{~J}_{\mathrm{m}} \mathrm{m}^{-2}$. Cohesive rupture in the tissue was achieved with cyanoacrylate glue for an adhesion energy of $33 \pm 10 \mathrm{~J} \cdot \mathrm{m}^{-2}$. This value gives an estimation of the maximum adhesion energy that can be attained with those PEG films on the liver capsule. Such a value is very low compared to the ones produced by optimized surgical adhesives (100-1000 $\mathrm{J} . \mathrm{m}^{-2}$ ), which is due to the absence of viscous dissipation in the bulk of the studied PEG films. 

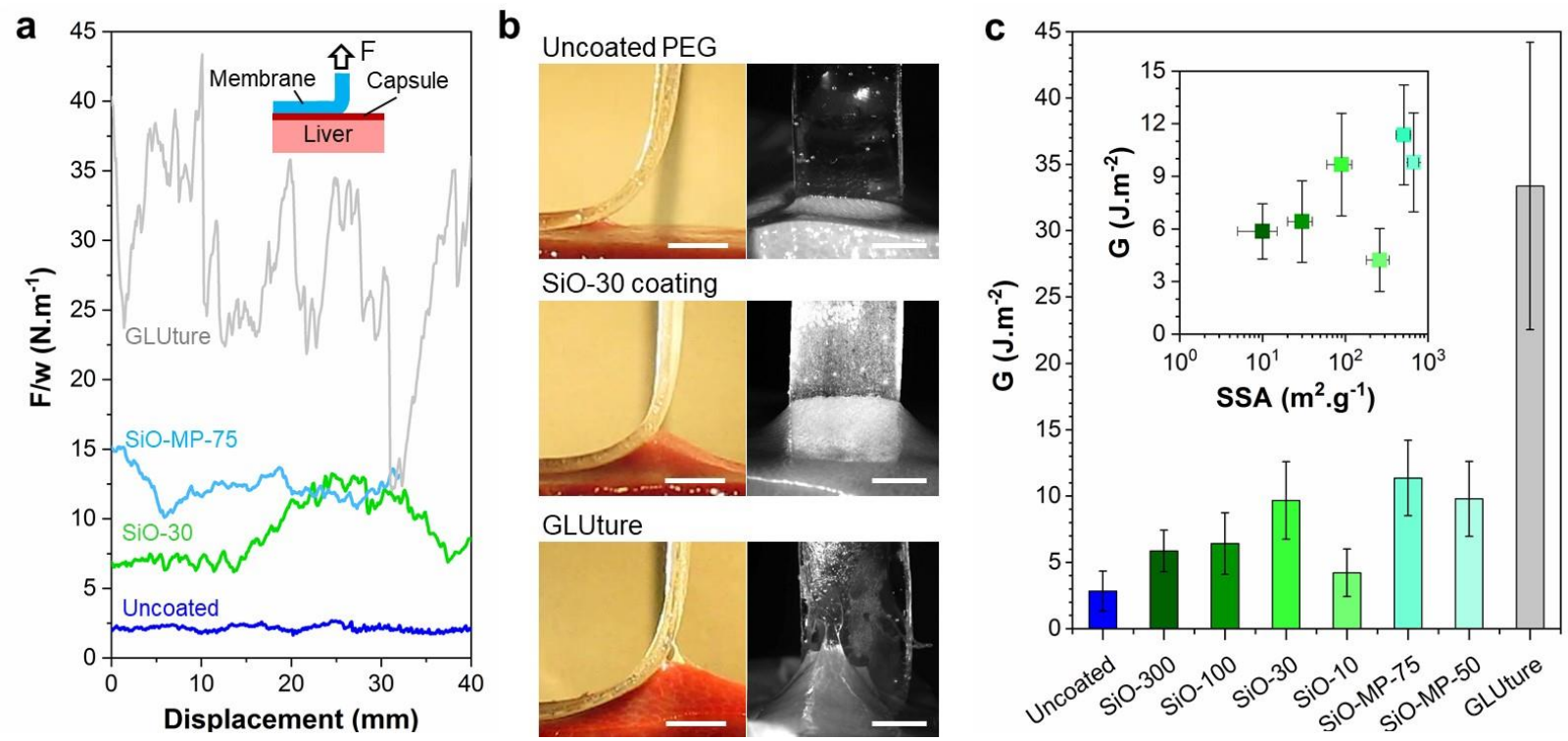

Figure 4: Coating selection by ex vivo adhesion. (a) Peeling force, F, normalized by the membrane width, $\mathrm{w}$, as a function of peeling displacement for uncoated PEG, SiO-30 and SiO-MP-75 coatings, and GLUture cyanoacrylate glue; (b) Side and front views of the peeling zones for an uncoated membrane (top), a SiO30 coated membrane (middle) and a membrane glued with GLUture cyanoacrylate glue (bottom) (scale bar: $5 \mathrm{~mm}$ ); (c) Adhesion energy as a function of membrane coating; Inset shows the adhesion energy, G, as a function of coating specific surface area, SSA. (Contact time: $5 \mathrm{~min}$ ).

We find that, apart from SiO-10 data, the adhesion energy increases with the specific surface area of the coating, as shown in the inset of Figure 4c. This trend is consistent with the idea that adhesion by particle bridging increases with the amount of surface onto which hydrogel and tissue macromolecules adsorb. ${ }^{16,21}$ Practically, high $S S A$ can be obtained by decreasing the nanoparticle size. Nevertheless, for very small nanoparticles $(<10 \mathrm{~nm})$, coating by simple brush spreading forms stacks of aggregates, therefore increasing the amount of weak inter-aggregate interfaces. These microstructural defects could explain the poor adhesion obtained with the SiO-10 coating. Accordingly, the adhesion energy of SiO-10 coated membranes is increased if an additional rinsing step is applied to remove weakly adsorbed aggregates (Figure S5). Alternatively, high SSA is also 
attainable with mesoporous particles, which size can be made large enough to reduce aggregation. This was achieved here with SiO-MP-50 and SiO-MP-75 which display a high specific surface area $\left(S S A=500-700 \mathrm{~m}^{-1}\right)$ and can be homogeneously spread with a brush (see Figure 2d). These mesoporous particles form the thinnest coatings $\left(m_{c}=0.15 \pm 0.10 \mathrm{mg} \cdot \mathrm{cm}^{-2}\right.$, Figure 2c) while producing the strongest ex vivo adhesion on the liver capsule $\left(G=11 \pm 4 \mathrm{~J} \cdot \mathrm{m}^{-2}\right.$, Figure $\left.4 \mathrm{c}\right)$.

\subsection{In vivo adhesion and coagulation-induced adhesion}

In vivo adhesion was assessed by pull-off tests on pig livers for 10 and 40 min contact times with the most adhesive coatings composed of plain (SiO-30) and mesoporous (SiO-MP-75) silica nanoparticles. Adhesion strength was measured by pulling off circular patches of PEG films using a portable equipment, as schematized in Figure 5a. The validity of this pull-off method was first verified ex vivo, as shown in Figure 5b. For a 10 min contact time on the capsule of explanted livers, both the SiO-30 and SiO-MP-75 coatings induce a 3-4 fold increase in pull-off strength, which is consistent with the increase in adhesion energy measured by peeling. Unlike for $90^{\circ}$ peeling experiments, the detachment process during pull-off involves a complex combination of shearing and peeling at varying angles. As a result, the measured pull-off strength is here a geometry dependent quantity. With this consideration in mind, it is still interesting to notice that the values of ex vivo adhesive strength produced with these silica coatings $(5 \pm 1 \mathrm{kPa})$ are lower but not that far from the values obtained by ex vivo tack tests with adhesive hydrogels on similar serous tissues: $16 \pm 2 \mathrm{kPa}$ for textured hydrogels with swelling microneedles on smooth serosal surface, ${ }^{12} 20 \pm 2 \mathrm{kPa}$ for double-side hydrogel tape on liver. ${ }^{15}$

In vivo results after a 10 min contact are very different from the ex vivo ones, as shown in Figure 5c. Most importantly, adhesion is found to be strongly reduced in vivo. The pull-off strength for 
both uncoated and coated films is 3 to 5 times lower than in the ex vivo case. This decrease in adhesion is attributed to the difference in tissue hydration between ex vivo and in vivo conditions, as shown recently with the same uncoated PEG films. ${ }^{14}$ Unlike ex vivo tissues, living tissues are actively perfused and the hydrogel-tissue interface is continuously wetted by tissue fluids. This is well evidenced by the exudation occurring at the surface of the liver during surgery (cf Figure S6). As a result, an interfacial water layer is formed continuously that prevents the hydrogel-tissue contact and reduces the possibility of adsorption on the coating particles due to a higher solvation and dilution of the macromolecules. ${ }^{48}$ Despite this change between ex vivo and in vivo conditions, an increase in pull-off strength is observed for SiO-30 $(p=0.205)$ and SiO-MP-75 $(p=0.003)$ coatings as compared to uncoated films. After $40 \mathrm{~min}$, this weak adhesion is maintained (Figure 5d) with a slight but not significant adhesive effect of the $\mathrm{SiO}-30$ coating as compared to the uncoated films $(p=0.129)$.

The effect of blood on adhesion was characterized as follows. A bleeding incision was performed in the spleen and the surface of the dry hydrogel patches was soaked in blood immediately prior to deposition on the liver capsule, as shown in Video S5. The corresponding values of pull-off strength are shown with hatched bars in Figures 5c and d for 10 and 40 min contact times, respectively. In the case of the uncoated films, the addition of blood at the tissue-hydrogel interface did not change adhesion. On the contrary, the presence of interfacial blood caused a remarkable enhancement of adhesion for the SiO-30 coated films. When compared to the uncoated films, the use of SiO-30 coatings with blood leads to a 2.5-fold $(p=0.003)$ and 4-fold $(p=0.002)$ increase in adhesion strength after 10 and $40 \mathrm{~min}$, respectively. These differences in adhesion are also well characterized by the maximum displacement of the liver surface reached during the detachment process, as underlined by double arrows in Figure 5e. 

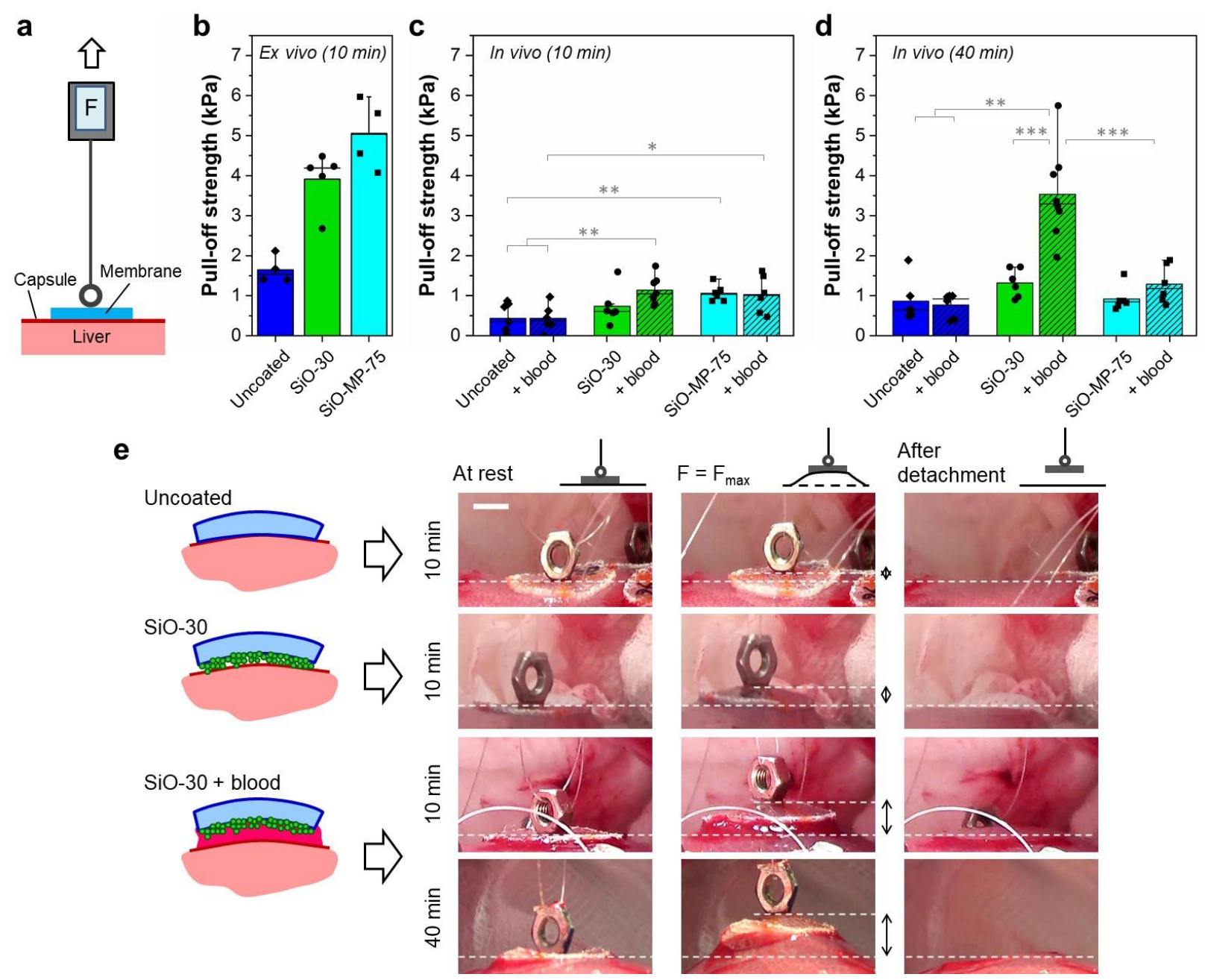

Figure 5: In vivo adhesion and coagulation-induced adhesion. (a) Schematic representation of the pulloff test; (b) Ex vivo measurements of pull-off strength on liver capsule for uncoated PEG and SiO-30, SiOMP-75 coatings (contact time: $10 \mathrm{~min}$ ); (c-d) In vivo measurements of pull-off strength on liver capsule without (plain) and with (hatched) wetting by blood prior to contact (contact time: $10 \mathrm{~min}$ (c) and $40 \mathrm{~min}$ (d)); (e) Pictures of membranes during in vivo pull-off for an uncoated membrane (10 min contact), a SiO30 coated membrane (10 min contact), a SiO-30 coated membrane wetted with blood (10 and $40 \mathrm{~min}$ contact). Double arrows indicate the maximum displacement applied to detach the membrane. (scale bar: 5 $\mathrm{mm})$. 
Unlike for the SiO-30 coating, the beneficial contribution of blood to adhesion was much lower for the mesoporous SiO-MP-75 coating. This difference can be related to the mechanism of bloodcoagulation induced by silica, which has been shown to rely on the activation of blood coagulation proteins. ${ }^{29,30}$ Such an activation process occurs through the surface adsorption of Factor XII which undergoes a conformational change exposing active sites that can trigger the coagulation cascade by activating other circulating proteins. As a result, the acceleration of coagulation depends on the amount of silica surface that is accessible to the circulating blood proteins. In the case of mesoporous SiO-MP-75 particles, blood coagulation proteins - especially Factor XII, which has a hydrodynamic diameter of about $7.5 \mathrm{~nm}^{30,49}$ - are too large to penetrate deeply inside the $6 \mathrm{~nm}$ pores. Therefore, it is unlikely that the internal surface of the pores contribute to the activation process. Accordingly, measurements of blood coagulation kinetics for a same concentration in particles showed no major differences between plain SiO-30 and mesoporous SiO-MP-75, despite a large difference in their SSA (Figure 2a). In addition, the area density of the coating is five times greater for SiO-30 than for SiO-MP-75 (Figure 2c). As a result, the maximum amount of silica surface that is accessible to blood per unit area of membrane is about twice lower with SiO-MP75 coatings $\left(\sim 230 \mathrm{~m}^{2} / \mathrm{m}^{2}\right)$ than with $\mathrm{SiO}-30$ coatings $\left(\sim 510 \mathrm{~m}^{2} / \mathrm{m}^{2}\right)$ (see SI). These results importantly suggest that both the amount of silica surface as well as its accessibility to blood are required to accelerate the formation of a clot gluing the interface.

\subsection{Hemostatic performance}

The combination of bioadhesive and procoagulant properties of SiO-30 coatings grant them with an interesting potential for hemostatic membranes. To verify this hypothesis, liver biopsies with a 6-mm diameter and a 5-mm depth were made in vivo using a biopsy punch as shown in Figure 6a 
and were covered with a patch as depicted in Figure 6b. Depending on the location, moderate to abundant bleeding rates ranging from 5 to 50 g. $\mathrm{min}^{-1}$ were obtained, as shown in Figure $6 \mathbf{c}$ for all the biopsies. The hemostatic power of membranes was probed by covering the bleeding wounds with a circular patch and applying a pressure manually during 30 s. Figure 6d shows the bleeding rates for each biopsy measured for 2 min after the release of manual pressure. For SiO-30 coatings, patches were applied on the most abundant bleeding wounds. Instantaneous containment of bleeding was obtained immediately after pressure release and no leakage was observed as shown in Video S6 and Figure 6e(top-right). Patches were removed by gentle peeling after 10 min and visual inspection of the bleeding area showed the presence of a cohesive blood clot filling the whole cavity and preventing further bleeding (Figure 6e(bottom-right)). Conversely, the uncoated PEG patch failed to contain bleeding as shown in Figure 6d. Blood continued to leak underneath the patch (Figure 6e(top-left)). No well-formed blood clot was observed after 10 min and bleeding resumed upon membrane removal (Figure 6e(bottom-left)). For this hemorrhage model, the hemostatic performance obtained with $\mathrm{SiO}-30$ coated membranes is found to be at least as good as that of a commercial hemostatic gauze made of an oxidized regenerated cellulose mesh (ORC) (Figure S7). In particular, the ORC was not as efficient in containing blood loss: some bleeding persisted after removal of manual pressure (biopsies 10\&11 in Figure S7b) and bleeding resumed after the removal of the mesh in some cases (Figure S7c). 


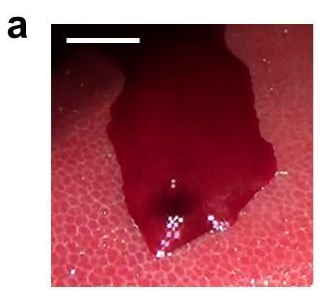

b

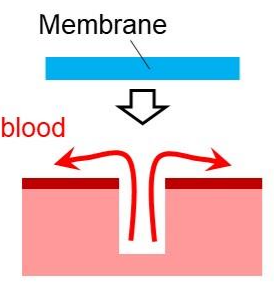

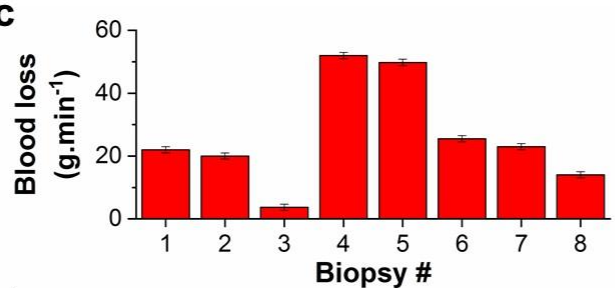

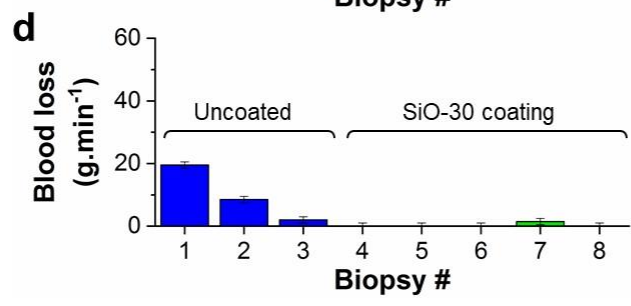

e

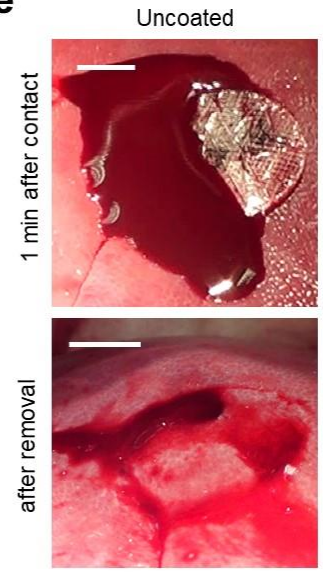

SiO-30 coating

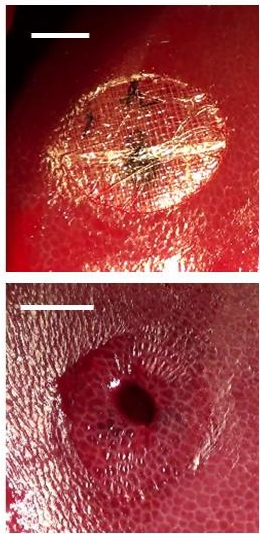

Figure 6: Hemostatic performance. (a) Schematic representation of the hemostasis protocol; (b) Picture of a bleeding biopsy (40 g.min $\left.{ }^{-1}\right)$; (c) Bleeding rates before membrane deposition; (d) Bleeding rates during the 2 minutes following deposition of uncoated and SiO-30 coated membranes; (e) Pictures of biopsies: 1 min after contact (top) and just after membrane removal (bottom). (scale bar: $1 \mathrm{~cm}$ ).

The question of the biocompatibility of such a particle-based approach is essential to ensure its safety and clinical relevance. A recent review by Murugadoss et al. ${ }^{50}$ compiling data for all types of silica nanoparticles shows that the no-observed-adverse-effect level for cytotoxicity of silica nanoparticles is at least of the order of $25 \mu \mathrm{g} / \mathrm{mL}$. The cytotoxicity of the main silica particles used in this work has been characterized in several in vitro studies. For the mesoporous nanoparticles (SiO-MP-50), 24 h incubation with 4T1 cells showed no cytotoxicity up to a concentration of 500 $\mu \mathrm{g} / \mathrm{mL}^{21}{ }^{21}$ For the plain SiO-30 nanoparticles (Ludox ${ }^{\circledR}$ TM50), $24 \mathrm{~h}$ incubation with HeLa cells showed little cytotoxicity up to a concentration of $400 \mu \mathrm{g} / \mathrm{mL}$ as well as an hemolytic activity for doses as low as $100 \mu \mathrm{g} / \mathrm{mL} .^{20}$ The same study by Shin et al. also showed that the destruction of red blood cells decreases when increasing the size of the silica nanoparticles with a 2-fold reduction in hemolysis rate at $100 \mu \mathrm{g} / \mathrm{mL}$ when comparing $22 \mathrm{~nm}$ and $105 \mathrm{~nm}$ particle diameters. Most interestingly, these cytotoxic and hemolytic effects can be mitigated by using more elaborate hybrid particles without compromising the procoagulant and adhesive property, as shown for 
instance by Matter et al. ${ }^{23}$ with bioglass/ceria nanoparticles and Shin et al. ${ }^{20}$ with tantalum oxide/silica core/shell nanoparticles. These results strongly suggest that the synergy between particle bridging and procoagulation is achievable with more biocompatible particle coatings, which is a determinant requirement for clinical use.

In the more specific context of internal surgery applications, previous works by Meddahi-Pellé et al. ${ }^{18}$ used the same SiO-30 nanoparticles to achieve tissue repair in a rat model. Direct injection of those particles into hepatic tissues ensured rapid wound closure and hemostasis followed by the formation of a thin fibrotic tissue in the wound area without altering the liver function after 3 days. More generally, the toxicity and the fate of silica nanoparticles has been the subject of numerous in vivo studies, mostly in rodent models..$^{50,51}$ These reports show that the toxic effects depend on many parameters including the size and shape of the nanoparticles, their chemical composition, their dose and their administration route. In the present approach, the confinement of blood flow between the coated membrane and the tissue allows to create adhesion and to arrest bleeding with a very low amount of SiO-30 nanoparticles $\left(\sim 0.5 \mathrm{mg} \cdot \mathrm{cm}^{-2}\right)$. Acute exposure to a large dose $(1-$ $1000 \mathrm{mg} / \mathrm{kg}$ body weight) of similar amorphous silica nanoparticles leads to adverse effects on various tissues and in particular on hepatic tissues in which the nanoparticles have the tendency to accumulate after being injected intravenously. ${ }^{52,53}$ Here, the amount of nanoparticles deposited on one patch $(<3 \mathrm{mg})$ corresponds to an exposure to a dose of the order of $0.05 \mathrm{mg} / \mathrm{kg}$ body weight in Human patients, which is several orders of magnitude lower than the doses typically tested in the previously mentioned toxicity surveys. Such a quantity of nanoparticles is also noticeably lower than the amount of silica-coated nanoparticles typically injected in rat models ( $\sim 10 \mathrm{mg})$ for imaging purposes. ${ }^{20}$ Given that only a fraction of those particles may leach out during an 
application, such low particle doses very substantially reduce the toxicity and possible thrombogenic risk in case of migration in the blood circulation. 


\section{CONCLUSION}

We demonstrated here that silica particle coatings provide a way to create adhesion between hydrogels and tissues in the presence of blood. Overall, ex vivo and in vivo experiments using PEG films deposited on the serous surface of porcine livers show that macromolecular adsorption onto particle aggregates creates an adhesion that is very sensitive to tissue hydration. Nevertheless, the in vivo adhesion strength can be reinforced manyfold by using procoagulant silica particles to induce the formation of a blood clot at the hydrogel-tissue interface. This mechanism requires that enough silica surface be exposed to blood in order to activate the coagulation cascade. Such coagulation-induced adhesion is persistent for long surgical times ( $>40 \mathrm{~min})$. It can be rapid and strong enough to seal internal wounds and achieve hemostasis.

In this work, elastic, non-dissipative membranes were intentionally used to probe the contribution of the particle coatings to the local debonding processes. These model systems are not suited for any particular biomedical application. However, thanks to the non-specificity and simplicity of coating by particle adsorption, this surface modification could be applied to other clinically relevant hydrogels, possibly involving extensive bulk dissipation. ${ }^{37}$ Furthermore, procoagulant particles containing various metal-oxides ${ }^{29}$ exhibit numerous clinically relevant properties such as contrast enhancement, ${ }^{18}$ antioxidant ${ }^{23}$ or antimicrobial ${ }^{54}$ effects, which offers many opportunities to design multifunctional bioadhesive hydrogel surfaces. The very low doses required to form an adhesive procoagulant coating suggest that functionality could be achieved with low toxicity and little alteration of the tissues, which would justify the realization of in vivo biocompatibility studies. 


\section{ASSOCIATED CONTENT}

Supporting Information. More details about the estimation of the accessible surface area of coating as well as supplementary figures and videos are given in supplementary information. The following files are available free of charge.

Supplementary methods and figures (PDF)

Supplementary videos (AVI)

\section{AUTHOR INFORMATION}

\section{Corresponding Authors}

*Laurent Corté: laurent.corte@mines-paristech.fr

*Raphaël Michel: raphael.michel@cermav.cnrs.fr

\section{Present Addresses}

${ }^{\dagger}$ Raphaël Michel: Univ. Grenoble Alpes, Centre de Recherches sur les Macromolécules Végétales (CERMAV)-CNRS, 601, rue de la Chimie, BP 53, 38041 Grenoble Cedex 9, France

\section{ACKNOWLEDGMENT}

We thank L. Leibler for initiating this research as well as J. Legagneux for liver harvesting and B. Lécuelle for technical support during the in vivo experiments. We thank C. Van Robais (Rheolution Inc.) for technical support during coagulation measurements. Financial support of ANR (ANR-18-CE19-0022-04 NanoBioTape), PSL University (PSL-Chimie-2014 HemoSoftChem), MINES ParisTech and ESPCI Paris-PSL is acknowledged. G.-R.Y. acknowledges support from Korea Health Industry Development Institute (KHIDI) grant (HP20C0078). 


\section{REFERENCES}

1. Lutolf, M. P.; Lauer-Fields, J. L.; Schmoekel, H. G.; Metters, A. T.; Weber, F. E.; Fields, G. B.; Hubbell, J. A., Synthetic matrix metalloproteinase-sensitive hydrogels for the conduction of tissue regeneration: Engineering cell-invasion characteristics. Proceedings of the National Academy of Sciences 2003, 100 (9), 5413-5418.

2. Kim, K. D.; Wright, N. M., Polyethylene glycol hydrogel spinal sealant (DuraSeal spinal sealant) as an adjunct to sutured dural repair in the spine results of a prospective, multicenter, randomized controlled study. Spine 2011, 36 (23), 1906-1912.

3. Behrens, A. M.; Sikorski, M. J.; Kofinas, P., Hemostatic strategies for traumatic and surgical bleeding. Journal of biomedical materials research. Part A 2014, 102 (11), 4182-4194.

4. Peppas, N. A.; Hilt, J. Z.; Khademhosseini, A.; Langer, R., Hydrogels in biology and medicine: From molecular principles to bionanotechnology. Adv. Mater. 2006, 18 (11), 13451360 .

5. Urban, G. A.; Weiss, T., Hydrogels for biosensors. In Hydrogel Sensors and Actuators, Gerlach, G.; Arndt, K.-F., Eds. Springer-Verlag: Berlin Heidelberg, 2009, 197-220.

6. Antonio, L.; Damia, M.; R., F. L. J., Adhesive biomaterials for tissue reconstruction. Journal of Chemical Technology \& Biotechnology 2008, 83 (4), 464-472.

7. Ghobril, C.; Grinstaff, M. W., The chemistry and engineering of polymeric hydrogel adhesives for wound closure: a tutorial. Chem. Soc. Rev. 2015, 44 (7), 1820-1835.

8. Oliva, N.; Artzi N. Injectable hydrogels as tissue adhesives. In Injectable Hydrogels for Regenerative Engineering, Nair, L.S. Ed. Imperial College Press, 2016, 239-273.

9. Zhang, W.; Wang, R.; Sun, Z.; Zhu, X.; Zhao, Q.; Zhang, T.; Cholewinski, A.; Yang, F.; Zhao, B.; Pinnaratip, R.; Forooshani, P. K.; Lee, B. P., Catechol-functionalized hydrogels: biomimetic design, adhesion mechanism, and biomedical applications. Chem. Soc. Rev. 2020, 49 (2), 433-464.

10. Li, J.; Celiz, A. D.; Yang, J.; Yang, Q.; Wamala, I.; Whyte, W.; Seo, B. R.; Vasilyev, N. V.; Vlassak, J. J.; Suo, Z.; Mooney, D. J., Tough adhesives for diverse wet surfaces. Science 2017, 357 (6349), 378.

11. Heinzmann, C.; Weder, C.; de Espinosa, L. M., Supramolecular polymer adhesives: advanced materials inspired by nature. Chem. Soc. Rev. 2016, 45 (2), 342-358.

12. Yang, S. Y.; O'Cearbhaill, E. D.; Sisk, G. C.; Park, K. M.; Cho, W. K.; Villiger, M.; Bouma, B. E.; Pomahac, B.; Karp, J. M., A bio-inspired swellable microneedle adhesive for mechanical interlocking with tissue. Nat. Commun. 2013, 4, 1702.

13. Park, H.-H.; Seong, M.; Sun, K.; Ko, H.; Kim S. M.; Jeong, H. E., Flexible and shape reconfigurable hydrogel interlocking adhesives for high adhesion in wet environments based on anisotropic swelling of hydrogel microstructures. ACS Macro Lett. 2017, 6, 1325-1330. 
14. Michel, R.; Poirier, L.; van Poelvoorde, Q.; Legagneux, J.; Manassero, M.; Corté, L., Interfacial fluid transport is a key to hydrogel bioadhesion. Proceedings of the National Academy of Sciences 2019, 116 (3), 738.

15. Yuk, H.; Varela, C. E.; Nabzdyk, C. S.; Mao, X.; Padera, R. F.; Roche, E. T.; Zhao, X., Dry double-sided tape for adhesion of wet tissues and devices. Nature 2019, 575 (7781), 169174.

16. Rose, S.; Prevoteau, A.; Elziere, P.; Hourdet, D.; Marcellan, A.; Leibler, L., Nanoparticle solutions as adhesives for gels and biological tissues. Nature 2014, 505 (7483), 382-385.

17. Yang, J.; Bai, R.; Suo, Z., Topological adhesion of wet materials. Adv. Mater. 2018, 30 (25), 1800671.

18. Meddahi-Pellé, A.; Legrand, A.; Marcellan, A.; Louedec, L.; Letourneur, D.; Leibler, L., Organ repair, hemostasis, and in vivo bonding of medical devices by aqueous solutions of nanoparticles. Angew. Chem.-Int. Edit. 2014, 53 (25), 6369-6373.

19. Pinnaratip, R.; Bhuiyan, M. S. A.; Meyers, K.; Rajachar, R. M.; Lee, B. P., Multifunctional biomedical adhesives. Adv. Healthc. Mater. 2019, 8 (11), 1801568.

20. Shin, K.; Choi, J. W.; Ko, G.; Baik, S.; Kim, D.; Park, O. K.; Lee, K.; Cho, H. R.; Han, S. I.; Lee, S. H.; Lee, D. J.; Lee, N.; Kim, H.-C.; Hyeon, T., Multifunctional nanoparticles as a tissue adhesive and an injectable marker for image-guided procedures. Nat. Commun. 2017, 8, 15807-15807.

21. Kim, J.-H.; Kim, H.; Choi, Y.; Lee, D. S.; Kim, J.; Yi, G.-R., Colloidal mesoporous silica nanoparticles as strong adhesives for hydrogels and biological tissues. ACS Appl. Mater. Interfaces 2017, 9 (37), 31469-31477.

22. Lu, M.-M.; Bai, J.; Shao, D.; Qiu, J.; Li, M.; Zheng, X.; Xiao, Y.; Wang, Z.; Chang, Z.M.; Chen, L.; Dong, W.-F.; Tang, C.-B., Antibacterial and biodegradable tissue nano-adhesives for rapid wound closure. Int. J. Nanomed. 2018, 13, 5849-5863.

23. Matter, M. T.; Starsich, F.; Galli, M.; Hilber, M.; Schlegel, A. A.; Bertazzo, S.; Pratsinis, S. E.; Herrmann, I. K., Developing a tissue glue by engineering the adhesive and hemostatic properties of metal oxide nanoparticles. Nanoscale 2017, 9 (24), 8418-8426.

24. Margolis, J., Effect of colloidal silica on blood coagulation. Australian Journal of Experimental Biology and Medical Science 1961, 39 (3), 249-258.

25. Tavano, R.; Segat, D.; Reddi, E.; Kos, J.; Rojnik, M.; Kocbek, P.; Iratni, S.; Scheglmann, D.; Colucci, M.; Echevarria, I. M.; Selvestrel, F.; Mancin, F.; Papini, E., Procoagulant properties of bare and highly PEGylated vinyl-modified silica nanoparticles. Nanomedicine 2010, 5 (6), 881-96.

26. Jiang, L. Z.; Li, Y. B.; Li, Y.; Guo, C. X.; Yu, Y. B.; Zou, Y.; Yang, Y. M.; Yu, Y.; Duan, J. C.; Geng, W. J.; Li, Q. L.; Sun, Z. W., Silica nanoparticles induced the pre-thrombotic state in rats via activation of coagulation factor XII and the JNK-NF-kappa B/AP-1 pathway. Toxicol. Res. 2015, 4 (6), 1453-1464. 
27. Hursey, F. X.; Dechene, F. J. Method of treating wounds. Patent US4822349A, 1989.

28. Marris, E., The war against wounds. Nature 2007, 446, 369-371.

29. Ostomel, T. A.; Shi, Q.; Stoimenov, P. K.; Stucky, G. D., Metal oxide surface charge mediated hemostasis. Langmuir 2007, 23 (22), 11233-11238.

30. Hao, F.; Liu, Q. S.; Chen, X.; Zhao, X.; Zhou, Q.; Liao, C.; Jiang, G., Exploring the heterogeneity of nanoparticles in their interactions with plasma coagulation Factor XII. ACS Nano 2019, 13 (2), 1990-2003.

31. Qiu, Y.; Brown, A. C.; Myers, D. R.; Sakurai, Y.; Mannino, R. G.; Tran, R.; Ahn, B.; Hardy, E. T.; Kee, M. F.; Kumar, S.; Bao, G.; Barker, T. H.; Lam, W. A., Platelet mechanosensing of substrate stiffness during clot formation mediates adhesion, spreading, and activation. Proc. Natl. Acad. Sci. U. S. A. 2014, 111 (40), 14430-14435.

32. Corbalan, J.; Medina, C.; Jacoby, A.; Malinski, T.; Radomski, M., Amorphous silica nanoparticles aggregate human platelets: potential implications for vascular homeostasis. Int. J. Nanomed. 2012, 7, 631-639.

33. Spotnitz, W. D., Fibrin sealant: the only approved hemostat, sealant, and adhesive - a laboratory and clinical perspective. ISRN Surgery 2014, 2014.

34. Bouten, P. J. M.; Zonjee, M.; Bender, J.; Yauw, S. T. K.; van Goor, H.; van Hest, J. C. M.; Hoogenboom, R., The chemistry of tissue adhesive materials. Prog. Polym. Sci. 2014, 39 (7), 1375-1405.

35. Roy, C. K.; Guo, H. L.; Sun, T. L.; Ihsan, A. B.; Kurokawa, T.; Takahata, M.; Nonoyama, T.; Nakajima, T.; Gong, J. P., Self-adjustable adhesion of polyampholyte hydrogels. Adv. Mater. 2015, 27 (45), 7344-7348.

36. Shin, J.; Lee, J. S.; Lee, C.; Park, H.-J.; Yang, K.; Jin, Y.; Ryu, J. H.; Hong, K. S.; Moon, S.-H.; Chung, H.-M.; Yang, H. S.; Um, S. H.; Oh, J.-W.; Kim, D.-I.; Lee, H.; Cho, S.W., Tissue adhesive catechol-modified hyaluronic acid hydrogel for effective, minimally invasive cell therapy. Advanced Functional Materials 2015, 25 (25), 3814-3824.

37. Yang, J.; Bai, R.; Chen, B.; Suo, Z., Hydrogel adhesion: a supramolecular synergy of chemistry, topology, and mechanics. Advanced Functional Materials 2020, 30, 1901693.

38. Strange, E. D.; Dahms, M. P.; Benedict, R. C.; Woychik, J. H., Changes in connective tissue histology in freeze-thaw cycled and refrigerated pork liver. Journal of Food Science 1985, 50 (5), 1484-1485.

39. Stöber, W.; Fink, A.; Bohn, E., Controlled growth of monodisperse silica spheres in the micron size range. J. Colloid Interface Sci. 1968, 26 (1), 62-69.

40. Nandiyanto, A. B. D.; Kim, S.-G.; Iskandar, F.; Okuyama, K., Synthesis of spherical mesoporous silica nanoparticles with nanometer-size controllable pores and outer diameters. Microporous and Mesoporous Materials 2009, 120 (3), 447-453.

41. Kendall, K., Thin-film peeling-Elastic term. J. Phys. D Appl. Phys. 1975, 8, 1449-1452. 
42. Peng, Z.L.; Chen, S.H., Effect of bending stiffness on the peeling behavior of an elastic thin film on a rigid substrate. Phys. Rev. E 2015, 91(4), 042401.

43. Leary, S., AVMA Guidelines for the euthanasia of animals: 2013 edition. American Veterinary Medical Association: Schaumburg, IL, 2013.

44. Wang, W.-N.; Lenggoro, I. W.; Okuyama, K., Dispersion and aggregation of nanoparticles derived from colloidal droplets under low-pressure conditions. J. Colloid Interface Sci. 2005, 288 (2), 423-431.

45. Shrestha, S.; Wang, B.; Dutta, P., Nanoparticle processing: understanding and controlling aggregation. Advances in Colloid and Interface Science 2020, 279, 102162.

46. Derosa, R. L.; Trapasso, J. A., Poly(ethylene glycol) interactions with alumina and silica powders determined via DRIFT. Journal of Materials Science 2002, 37 (6), 1079-1082.

47. Kim, S. Y.; Zukoski, C. F., Molecular weight effects on particle and polymer microstructure in concentrated polymer solutions. Macromolecules 2013, 46 (16), 6634-6643.

48. Hofman, A. H.; van Hees, I. A.; Yang, J.; Kamperman, M., Bioinspired underwater adhesives by using the supramolecular toolbox. Adv. Mater. 2018, 30 (19), 1704640.

49. Sanfins, E.; Augustsson, C.; Dahlbäck, B.; Linse, S.; Cedervall, T., Size-dependent effects of nanoparticles on enzymes in the blood coagulation cascade. Nano Letters 2014, 14 (8), 47364744.

50. Murugadoss, S.; Lison, D.; Godderis, L.; Van Den Brule, S.; Mast, J.; Brassinne, F.; Sebaihi, N.; Hoet, P. H., Toxicology of silica nanoparticles: an update. Archives of Toxicology 2017, 91 (9), 2967-3010.

51. Napierska, D.; Thomassen, L. C. J.; Lison, D.; Martens, J. A.; Hoet, P. H., The nanosilica hazard: another variable entity. Particle and Fibre Toxicology 2010, 7 (1), 39.

52. Nabeshi, H.; Yoshikawa, T.; Matsuyama, K.; Nakazato, Y.; Matsuo, K.; Arimori, A.; Isobe, M.; Tochigi, S.; Kondoh, S.; Hirai, T.; Akase, T.; Yamashita, T.; Yamashita, K.; Yoshida, T.; Nagano, K.; Abe, Y.; Yoshioka, Y.; Kamada, H.; Imazawa, T.; Itoh, N.; Nakagawa, S.; Mayumi, T.; Tsunoda, S.-i.; Tsutsumi, Y., Systemic distribution, nuclear entry and cytotoxicity of amorphous nanosilica following topical application. Biomaterials 2011, 32 (11), 2713-2724.

53. Yu, Y.; Li, Y.; Wang, W.; Jin, M.; Du, Z.; Li, Y.; Duan, J.; Yu, Y.; Sun, Z., Acute toxicity of amorphous silica nanoparticles in intravenously exposed ICR mice. PLOS ONE 2013, 8 (4), e61346.

54. Raghunath, A.; Perumal, E., Metal oxide nanoparticles as antimicrobial agents: a promise for the future. International Journal of Antimicrobial Agents 2017, 49 (2), 137-152. 


\section{Supporting Information}

\section{Hydrogel-tissue adhesion using blood coagulation induced by silica nanoparticle coatings}

Raphä̈l Michel, ${ }^{1 *}$ Maïlie Roquart, ${ }^{1,2}$ Elodie Llusar, ${ }^{1}$ Fabrice Gaslain, ${ }^{2}$ Sophie Norvez, ${ }^{1}$ JaeSeon Baik, ${ }^{3}$ Gi-Ra Yi, ${ }^{3}$ Mathieu Manassero, ${ }^{4,5}$ Laurent Corté ${ }^{1,2 *}$

${ }^{1}$ Molecular, Macromolecular Chemistry, and Materials, ESPCI Paris, CNRS, PSL Research University, 75005 Paris, France

${ }^{2}$ Centre des Matériaux, MINES ParisTech, CNRS, PSL Research University, 91003 Evry, France

${ }^{3}$ School of Chemical Engineering, Sungkyunkwan University, Suwon 16419, Republic of Korea

${ }^{4}$ Service de chirurgie, École Nationale Vétérinaire d'Alfort, 94700 Maisons-Alfort, France.

${ }^{5}$ Laboratoire de Biologie, Bioingénierie et Bioimagerie Ostéo-Articulaire, CNRS UMR 7052, 75010

Paris, France

*Corresponding authors :

Raphaël Michel (raphael.michel@,cermav.cnrs.fr)

Laurent Corté (1aurent.corte@mines-paristech.fr) 


\section{SUPPLEMENTARY METHODS}

\section{Estimation of the maximum accessible coating surface}

The maximum amount of silica surface that is accessible to blood proteins per surface area of coating, $\alpha$, is estimated as follows. We assume that blood proteins are only exposed to the outside surface of silica particles. As a result, $\alpha$ writes as:

$$
\alpha=\frac{m_{c}}{M_{p}} S_{p}
$$

where $m_{c}$ is the mass of deposited coating per surface area, $M_{p}$ and $S_{p}$ are the mass and outer surface of one particle, respectively.

- For plain spherical particles like $\mathrm{SiO}-30, \alpha$ is given by:

$$
\alpha=\frac{6 m_{c}}{\rho_{\mathrm{SiO}_{2}} d}
$$

where $d$ is the particle diameter and $\rho_{\mathrm{SiO}_{2}}$ is the density of amorphous silica $\left(2.20 \mathrm{~g} \cdot \mathrm{cm}^{-3}\right)$.

- For mesoporous spherical particles like SiO-MP-75, one needs to consider the effect of porosity on the mass of one particle which is given by:

$$
M_{p}=\rho_{\mathrm{SiO}_{2}}\left(V_{p}-v_{\text {pore }} M_{p}\right)
$$

where $V_{p}$ is the volume of one particle and $v_{\text {pore }}$ is its specific pore volume $\left(1.49 \mathrm{~cm}^{3} \cdot \mathrm{g}^{-1}\right){ }^{1}$

Therefore, $\alpha$ is given by:

$$
\alpha=\frac{6 m_{c}}{\rho_{\mathrm{SiO}_{2}} d}\left(1+\rho_{\mathrm{SiO}_{2}} v_{\text {pore }}\right)
$$




\section{SUPPLEMENTARY FIGURES}

A

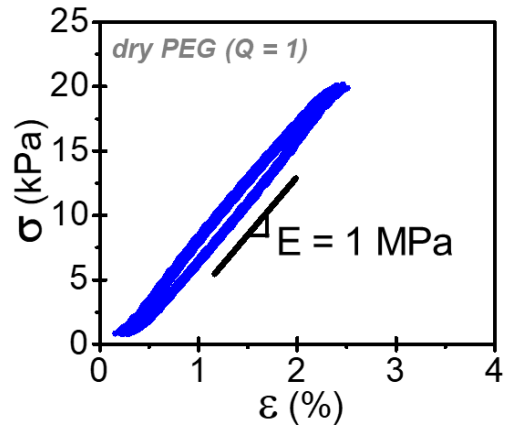

B

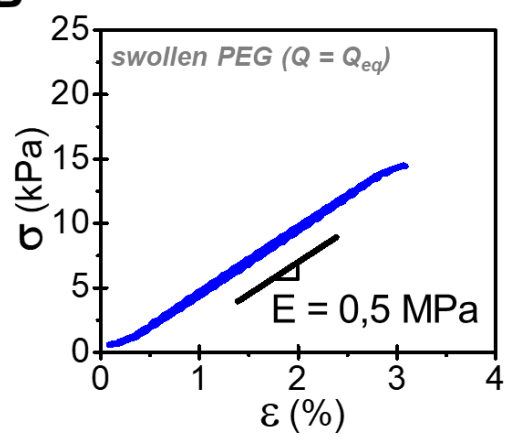

Fig. S1: Tensile stress-strain curves of PEG films under one loading-unloading cycle in dry state (A) and swollen to equilibrium in water (B) starring the Young's modulus for both systems. Corresponding methods are given in reference 2 . 


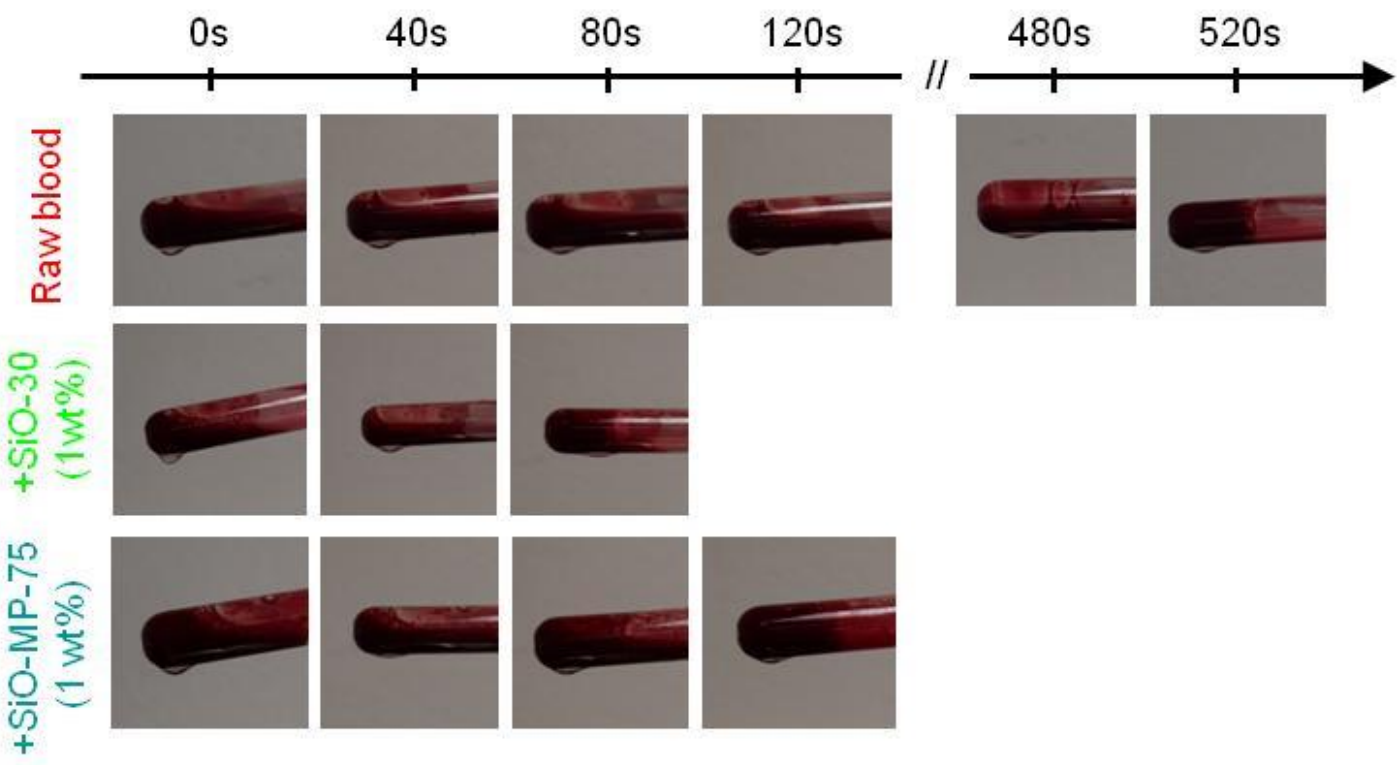

Figure S2: Blood coagulation kinetics. Pictures of tilted test tubes with freshly sampled pig blood, without particles, with 1wt\% SiO-30 and 1wt\% SiO-MP-75. 

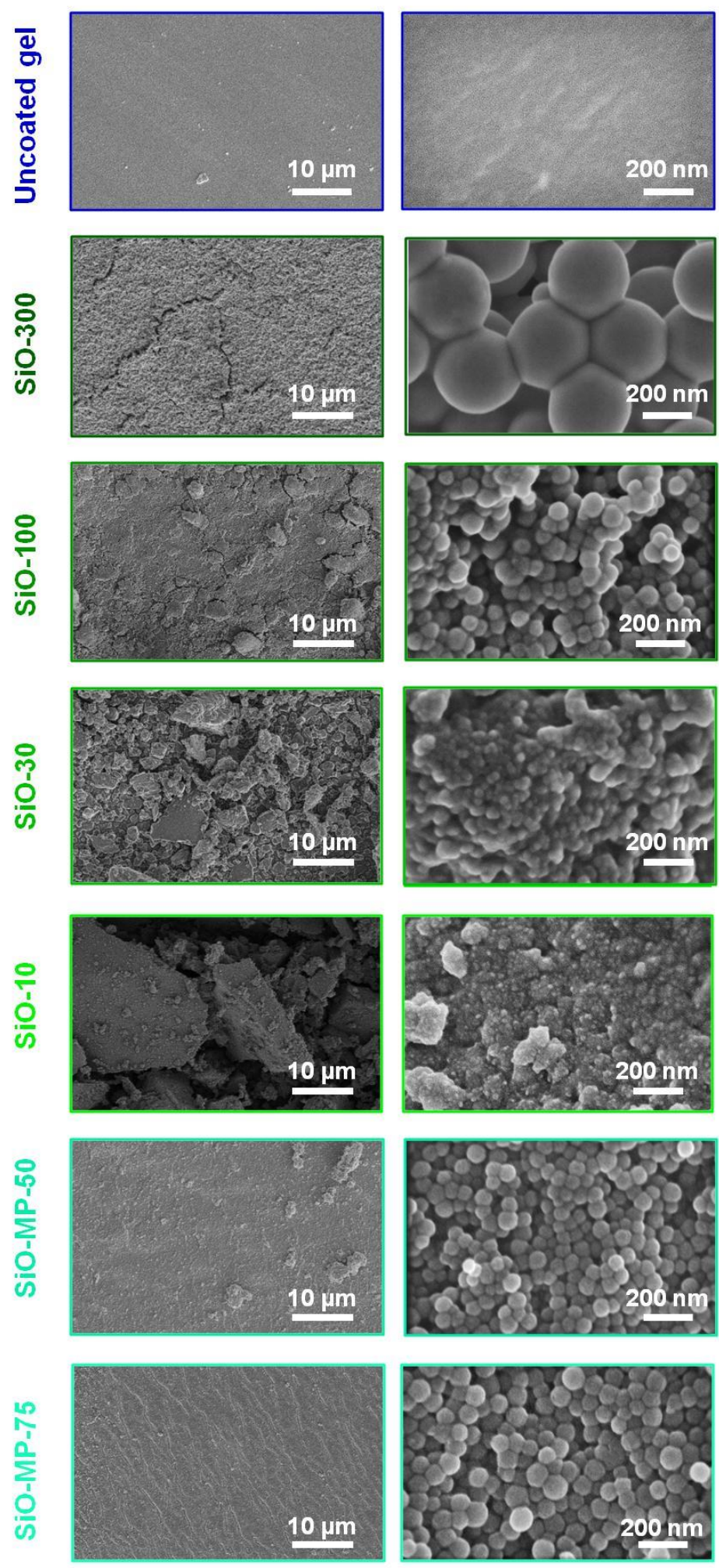

Figure S3: SEM observations of all the studied membranes 

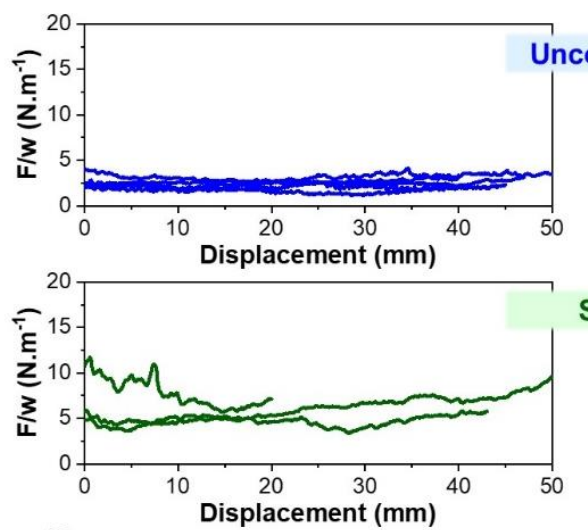

SiO-300
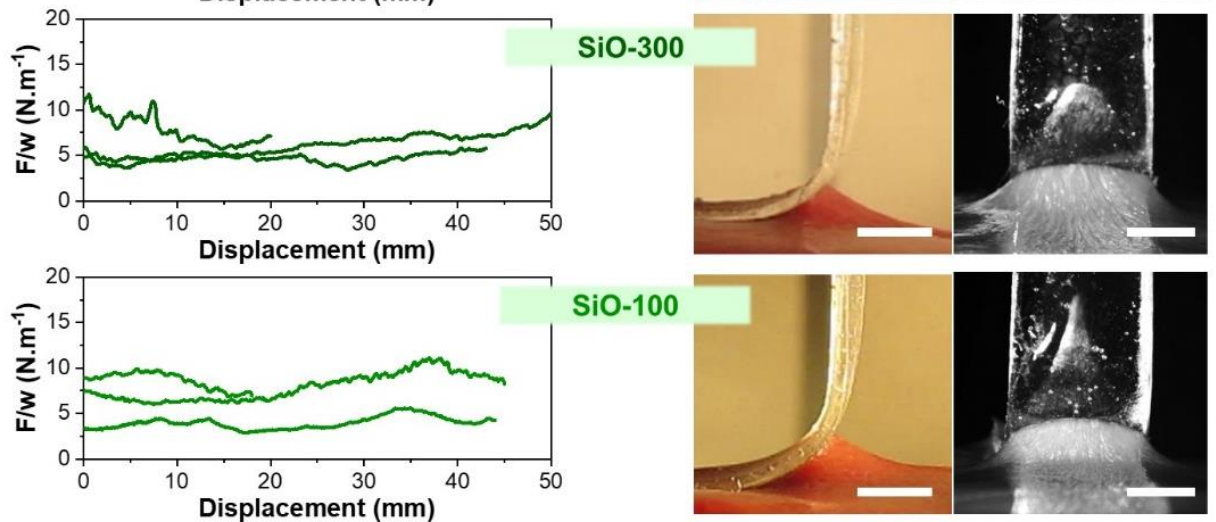

SiO-100
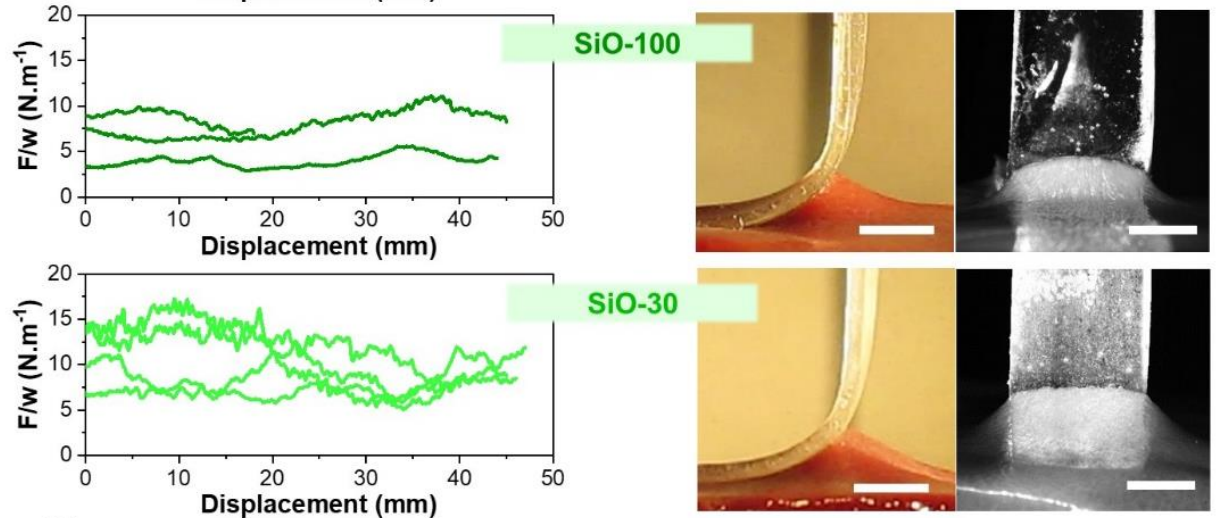

$\mathrm{SiO}-30$
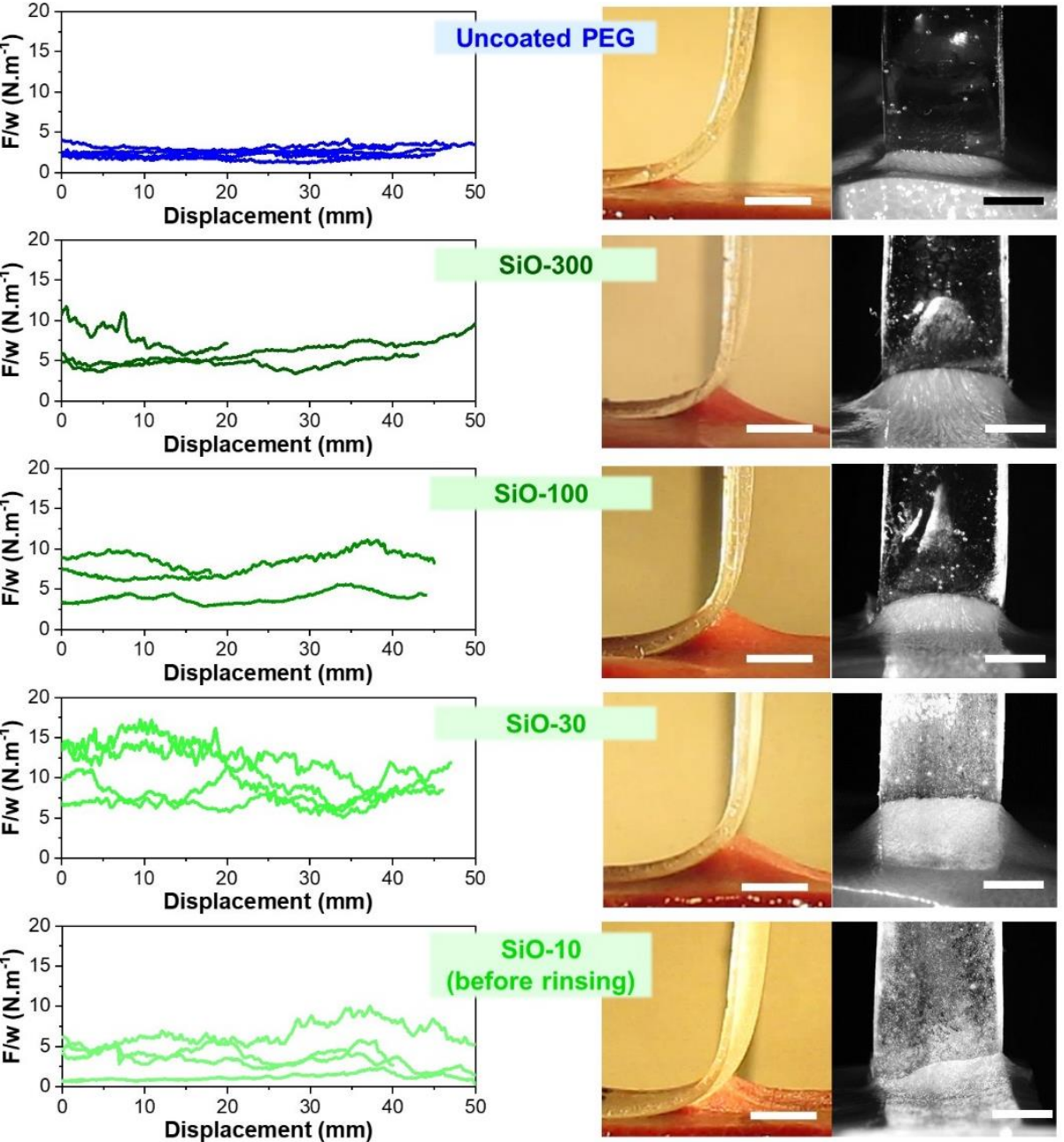

SiO-10
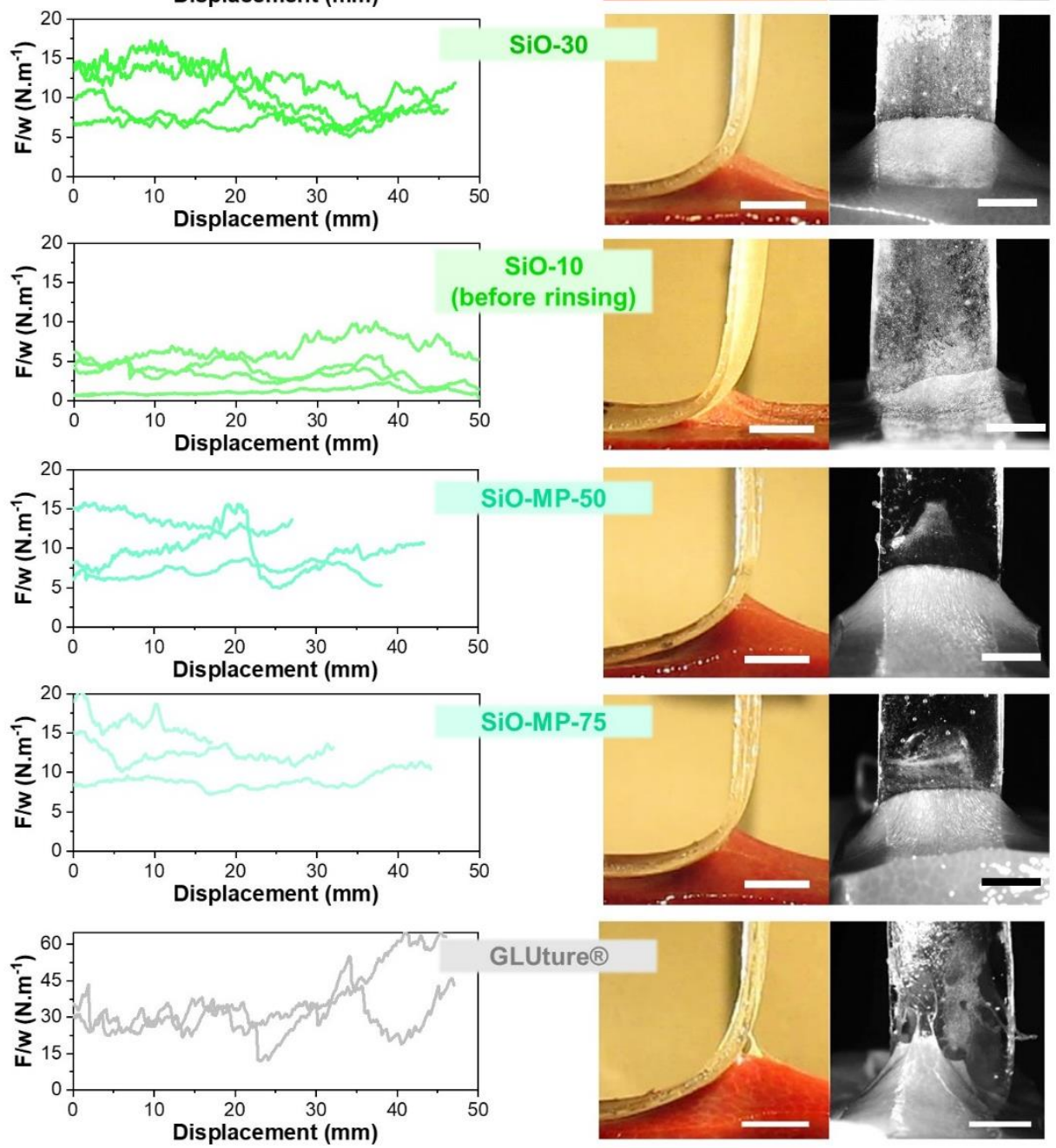

Figure S4: Ex vivo peeling force and snapshots (side and front view) of the peeling experiments obtained for all the studied membranes. 

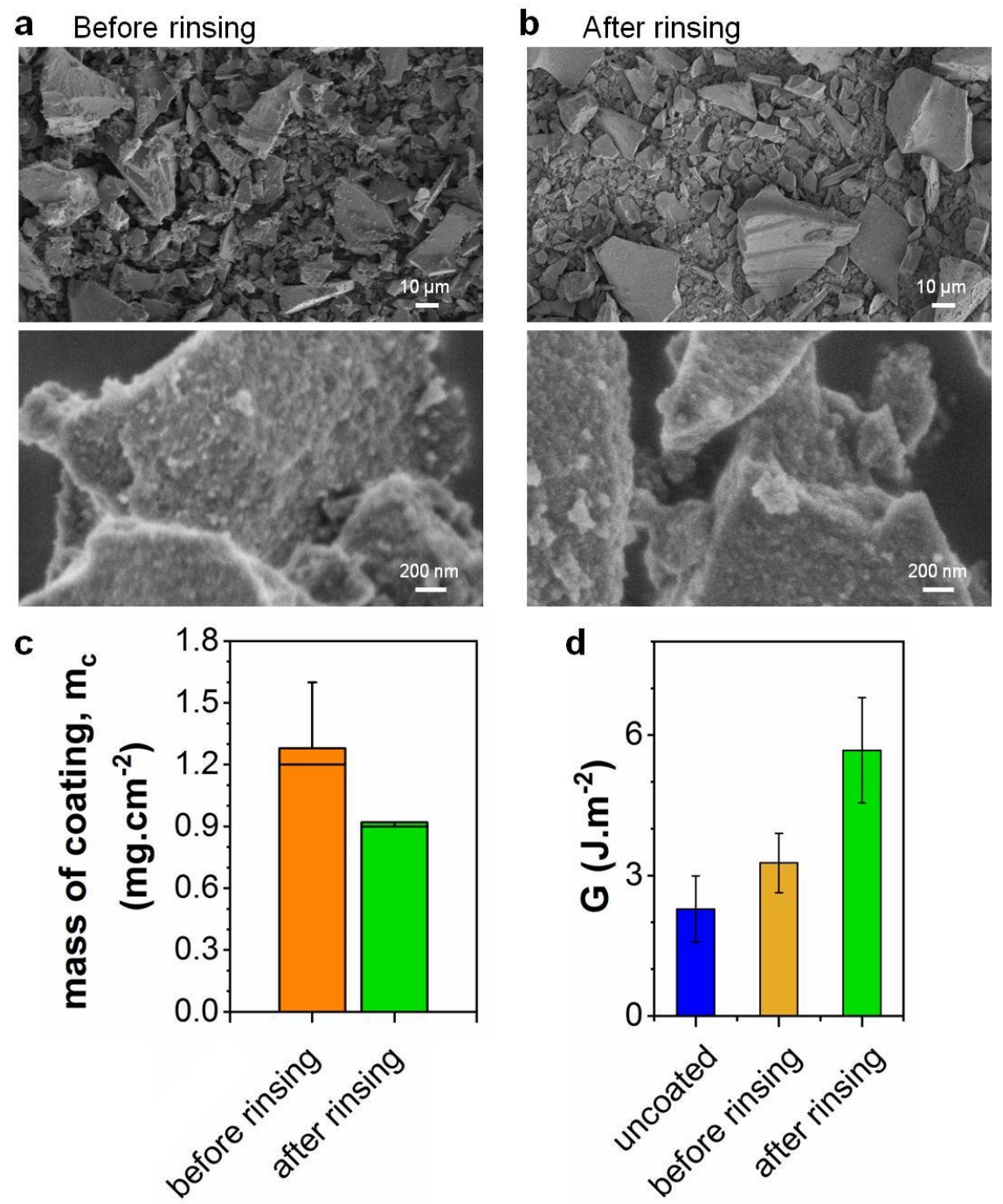

Figure S5: Effect of rinsing to remove weakly adsorbed aggregates on adhesion performance of SiO10 coatings. Rinsed SiO-10 coated membranes were obtained by immersion in water for 30 min followed by drying in vacuum oven at $60^{\circ} \mathrm{C}$ for $6 \mathrm{~h}$. (a) mass of deposited coating per unit area before and after rinsing; (b) Adhesion energy measured by $90^{\circ}$ peeling on ex vivo porcine liver capsule (contact time: 5 $\min )$. 


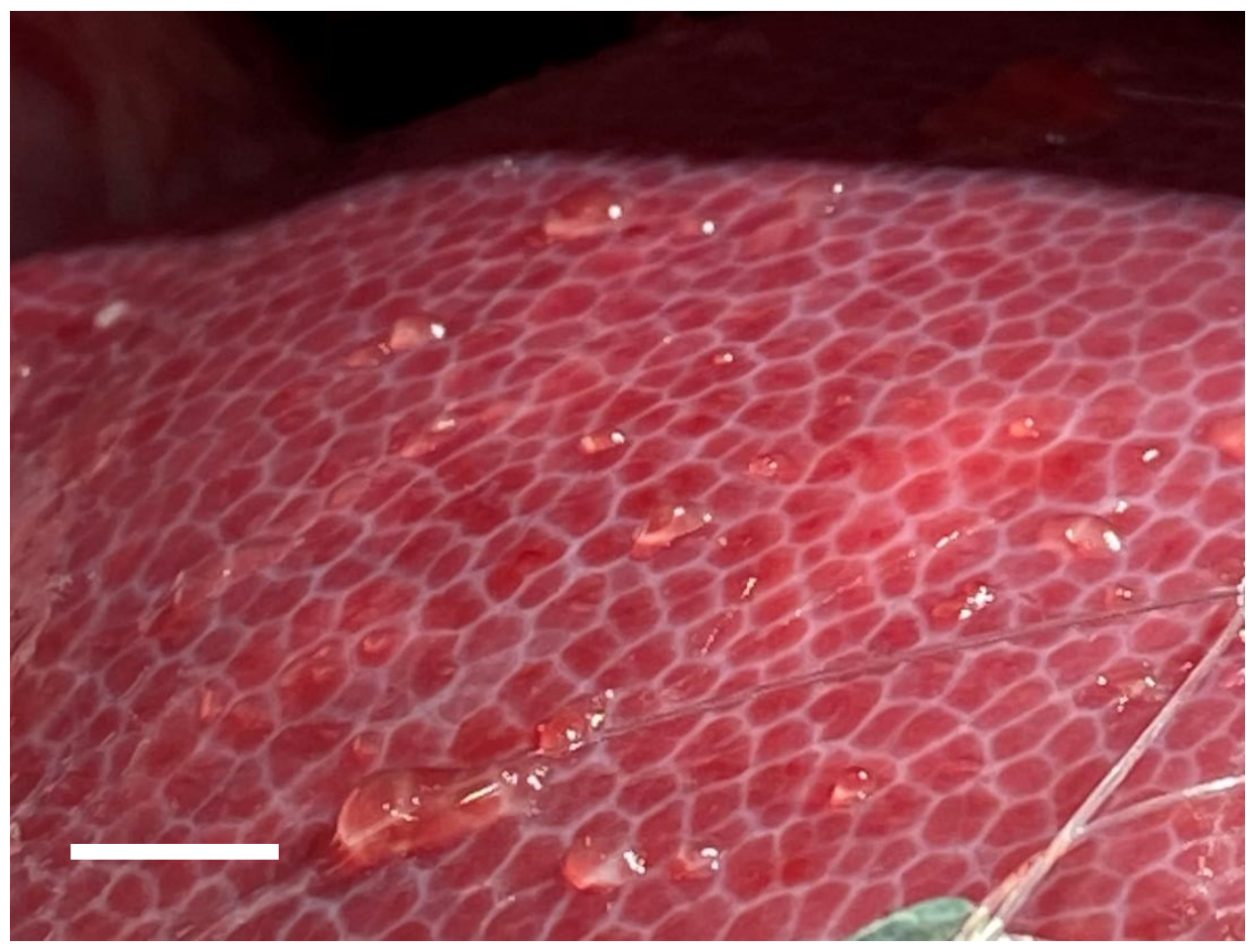

Figure S6: Exudation of fluid at the liver surface. Picture taken during in vivo experiments showing droplets resulting from the exudation of physiological fluids through the capsule of porcine liver. This phenomenon was observed on liver surfaces that were left exposed to air for a prolonged time of the order of 30-60 min (scale bar: $5 \mathrm{~mm}$ ). 

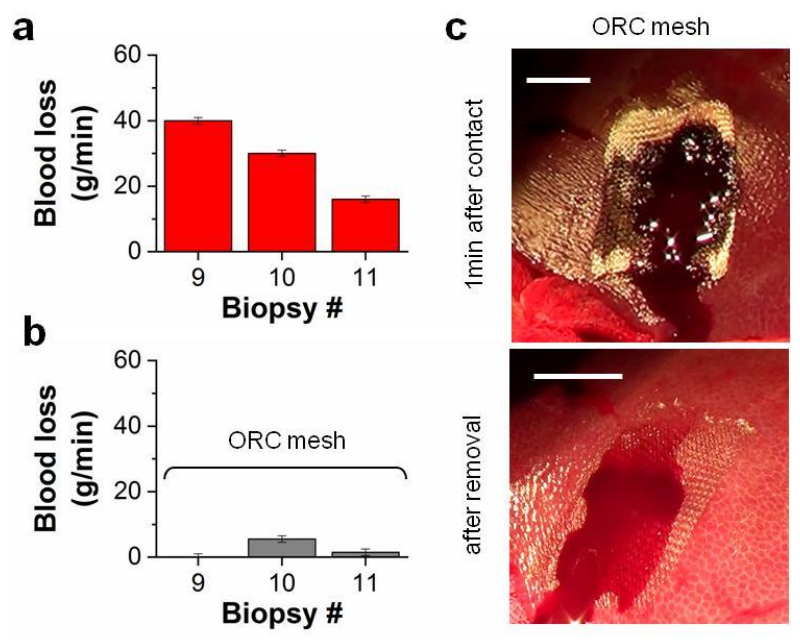

Figure S7: Hemostatic performance with commercial hemostat. (a) Bleeding rates before membrane deposition; (b) Bleeding rates during the 2 minutes following deposition of oxidized regenerated cellulose meshes (ORC); (c) Pictures of biopsies: 1 min after contact (top) and just after mesh removal (bottom). (scale bar: $1 \mathrm{~cm}$ ). 


\section{SUPPLEMENTARY VIDEO CAPTIONS}

Video S1: Video of the blood coagulation kinetics showing tilted tubes for freshly sampled pig blood, without particles, with $1 \mathrm{wt} \% \mathrm{SiO}-30$ and $1 \mathrm{wt} \% \mathrm{SiO}-\mathrm{MP}-75$.

Video S2: Side and front video of the ex vivo peeling of an uncoated PEG ribbon on liver capsule after 5 min of contact. (Accelerated 10 times; scale bar: $5 \mathrm{~mm}$ )

Video S3: Side and front video of the ex vivo peeling of a PEG ribbon with SiO-30 coating on liver capsule after $5 \mathrm{~min}$ of contact. (Accelerated 10 times; scale bar: $5 \mathrm{~mm}$ )

Video S4: Side and front video of the ex vivo peeling of a PEG ribbon glued on the liver capsule with surgical glue (GLUture $\left.{ }^{\circledR}\right)$ after 5 min of contact. (Accelerated 10 times; scale bar: $5 \mathrm{~mm}$ )

Video S5: Video of the experimental protocol of the wetting of a PEG film with blood and subsequent deposition on the liver capsule (accelerated 2.5 times).

Video S6: Video of a hemostasis experiment with a PEG film coated with SiO-30 nanoparticles. 


\section{SUPPLEMENTARY REFERENCES}

1. Kim, J.-H.; Kim, H.; Choi, Y.; Lee, D. S.; Kim, J.; Yi, G.-R., Colloidal Mesoporous Silica Nanoparticles as Strong Adhesives for Hydrogels and Biological Tissues. ACS Appl. Mater. Interfaces 2017, 9 (37), 31469-31477.

2. Michel, R.; Poirier, L.; van Poelvoorde, Q.; Legagneux, J.; Manassero, M.; Corté, L., Interfacial fluid transport is a key to hydrogel bioadhesion. Proceedings of the National Academy of Sciences 2019, 116 (3), 738. 